\title{
Speculative bubbles in the S\&P 500: was the tech bubble confined to the tech sector?
}

Article

Accepted Version

Anderson, K., Brooks, C. and Katsaris, A. (2010) Speculative bubbles in the S\&P 500: was the tech bubble confined to the tech sector? Journal of Empirical Finance, 17 (3). pp. 345-361. ISSN 0927-5398 doi:

https://doi.org/10.1016/j.jempfin.2009.12.004 Available at https://centaur.reading.ac.uk/18665/

It is advisable to refer to the publisher's version if you intend to cite from the work. See Guidance on citing.

To link to this article DOI: http://dx.doi.org/10.1016/j.jempfin.2009.12.004

Publisher: Elsevier

All outputs in CentAUR are protected by Intellectual Property Rights law, including copyright law. Copyright and IPR is retained by the creators or other copyright holders. Terms and conditions for use of this material are defined in the End User Agreement.

www.reading.ac.uk/centaur 
Central Archive at the University of Reading

Reading's research outputs online 
NOTICE: this is the author's version of a work that was accepted for publication in the Journal of Empirical Finance. Changes resulting from the publishing process, such as peer review, editing, corrections, structural formatting, and other quality control mechanisms may not be reflected in this document. Changes may have been made to this work since it was submitted for publication. A definitive version was subsequently published in the Journal of Empirical Finance, 17 (2010), DOI:10.1016/10.1016/j.jempfin.2009.12.004 


\title{
Speculative Bubbles in the S\&P 500: \\ Was the Tech Bubble Confined to the Tech Sector?
}

\author{
Keith Anderson, Chris Brooks* and Apostolos Katsaris \\ University of York, UK; ICMA Centre, University of Reading, UK; Caliburn Capital Partners LLP, UK
}

\begin{abstract}
This study tests for the presence of periodically, partially collapsing speculative bubbles in the sector indices of the S\&P 500 using a regime-switching approach. We also employ an augmented model that includes trading volume as a technical indicator to improve the ability of the model to time bubble collapses and to better capture the temporal variations in returns. We find that well over half of the S\&P 500 index by market capitalization and seven of its ten sector component indices exhibited at least some bubble-like behavior over our sample period. Thus the speculative bubble that grew in the 1990s and subsequently collapsed was surprisingly pervasive in the US equity market and it affected numerous sectors including financials and general industrials, rather than being confined to information technology, telecommunications and the media. In addition, we develop a joint model for cross-sectional contagion of bubbles across the sectors and we examine whether there is evidence for bubble spillovers.
\end{abstract}

This revised version: September 2008

Keywords: Stock market bubbles; fundamental values; dividends; regime switching; speculative bubble tests.

JEL Classifications: C51, C53, G12

Acknowledgement: The authors would like to thank an anonymous referee for a number of useful comments that substantially focused and improved upon a previous version of this paper. The usual disclaimer applies.

\footnotetext{
* Corresponding author: ICMA Centre, University of Reading, Whiteknights, Reading RG6 6BA, UK; tel:
} (+44) 118378 7809; fax: (+44) 118931 4741; e-mail: C.Brooks@ @rdg.ac.uk . 


\section{Introduction}

Equity markets have historically enjoyed periods of spectacular growth in prices followed by rapid reversals. Such phenomenal price movements have motivated the development of asset-pricing models that try to explain the evolution of prices as well as to produce profitable forecasts for investment decisions. Nevertheless, many of these models often fail to predict the movement of prices in financial markets accurately, especially in times of high volatility in asset returns. This failure is sometimes attributed to an inability of these models to capture 'fundamental values' accurately. Other researchers claim that, in certain periods, fundamental values seem to be irrelevant in the pricing of financial assets. The behavior of stock market prices prior to the 1929 and 1987 stock market crashes are the most frequently cited examples of such periods of fundamental value irrelevance (see for example White (1990), Rappoport and White (1994), Shiller (2000)). The evolution of stock market prices in these two periods has inspired the search for other factors, beyond fundamentals, that might affect market prices and thus cause their 'apparent' deviations from fundamental values. One possible explanation for these deviations is the presence of speculative bubbles.

Following Shiller's (1981) seminal paper, several indirect and direct methodologies have been developed to test for the presence of bubbles in equity, currency and commodities markets and in monetary data. Indirect tests are based on the identification of bubbles through an examination of the distributional properties of actual prices (or returns) and fundamental values (see for example Shiller (1981), LeRoy and Porter (1981), Blanchard and Watson (1982)), through tests for cointegrating relationships between actual prices and fundamental values (see Meese (1986), Campbell and Shiller (1987), Diba and Grossman (1988a), Hall et al. (1999)), ${ }^{1}$ or through an examination of the specifications of the present value relationship and the actual relationship between prices and dividends (see Meese (1986), West (1987), Dezhbakhsh and DemirgucKunt (1990)).

Since indirect tests are usually a joint test of bubble absence and of the validity of the present value model (see Kleidon (1986a,b), West (1988)), they are usually argued to provide only 'hints' of bubble presence and not proof. Direct tests by contrast examine the presence of specific forms of speculative bubbles by identifying the presence of bubble-like behavior in financial and macroeconomic data. Direct tests have focused on the presence of deterministic bubbles (Flood and Garber (1980), Salge (1997)), fads (Summers (1986), Cutler et al. (1991)) and on the presence of periodically collapsing speculative bubbles (McQueen

\footnotetext{
${ }^{1}$ Hall et al. (1999) formulate a test that is able to identify periodically collapsing speculative bubbles and as such, it can be classified as a direct bubble test. However, because it is based on the identification of periods of explosive behavior in macroeconomic data through a switching augmented Dickey Fuller test, we have classified it as an indirect test of bubble presence.
} 
and Thorley (1994), van Norden (1996), van Norden and Schaller (1999), Bohl (2000), Sornette and Johansen (1997)).

In an important paper, van Norden and Schaller (1999) ${ }^{2}$ (hereafter vNS) propose a switching regime speculative behavior model that tests for the presence of periodically partially collapsing speculative bubbles. vNS construct a switching model of returns with a state independent probability of switching regimes. Although direct tests find mixed evidence of speculative bubbles, all of these tests, with the exception of Sornette and Johansen (1997), assume that bubble crashes are exogenous events. However, it is usually thought that bubble collapses are a result of a change in investors' beliefs concerning the future of the bubble. Brooks and Katsaris (2005b) augment the model of vNS for testing for the presence of periodically partially collapsing speculative bubbles by including observed abnormal volume as a predictor of the time of the crash. They argue that abnormal volume is a predictor and a classifier of returns because it can provide information to investors about the belief of the market in the future of the bubble. Since all investors have access to information about past trading volume, upon the observation of increased volume in the market, they perceive that other investors are liquidating the bubbly asset and thus, they may rush to liquidate their holdings. This will cause a bubble collapse. Collapses, in this case, are caused endogenously since more investor selling leads to an increased supply of the asset.

A possible explanation for the initial drop followed by the significant increase in equity prices during the last 25 years of the twentieth century is offered by Zeira (1999). In his study, Zeira presents a model of stock market booms and crashes caused by the uncertainty investors face about fundamental values. In effect, market booms are caused by informational overshooting when new technologies are implemented in the production process and the limit of such technologies is unknown. Once the limit of this 'new' technology is reached, market participants realize that no further growth is possible and thus cause market prices to crash. This model can be transformed to explain market booms and crashes using the arrival of new investors to the market ('greater fools') or the liberalization of monetary policy by central banks. Zeira claims that this model is capable of partly explaining the booms and crashes of 1929, 1987 and the boom of the Information Technology Era, but for his model to be able to explain historical 'bubble-like' episodes would require that the arrival and 'death' of new technologies is synchronized and that investors are myopic

\footnotetext{
2 vNS's approach is based on previous work by van Norden and Schaller (1993) who examined whether apparent deviations from dividend based fundamentals are able to predict stock market crashes and rallies. In their original paper, they used data on the Toronto Stock Exchange Composite Index and found that the speculative behavior model has significant explanatory power for excess stock market returns, since the ex ante conditional probability of a bubble collapse increases prior to many actual stock market crashes and rallies.
} 
and do not adapt their expectations to information about the limits of the technology, revealed before the limit is reached. ${ }^{3}$

The variation in the prices of S\&P 500 stocks during the 1990s is particularly difficult to explain. One possible approach is presented by Greenwood and Jovanovic (1999) and Hobijn and Jovanovic (2000). In their studies, they present a model of technological change that can replicate booms and crashes observed in financial data and can explain stock market valuations during the last 25 years. The main suggestion of the model is that new technologies destroy old, incumbent firms ${ }^{4}$ once the success of the new technology is made known to the market. Since new technologies are rarely formed by listed companies, and because listed companies usually resist their implementation, stock market valuations are depressed once new technologies are invented. This is because once small innovative firms are listed on the market, investors shift their attention to such companies and neglect 'old' technology firms that have lower growth potential. However, this transition is smooth through time and thus stock market valuations may appear to be undervalued for prolonged periods. Hobijn and Jovanovic (2000) present empirical evidence that supports their theory and state that the low market valuations in the 1970s were a result of the anticipation of the information technology era, and that during this period, 'old' technology firms were rationally being sold by investors. This was because a large claim to future dividends was not listed in the stock market yet, since most innovation was performed by small private firms. Furthermore, their model suggests that the extraordinary growth of stock market valuations in the 1990s is the result of the long awaited productivity gains from the implementation of IT in the production process and the subsequent 'third industrial revolution'. However, the Hobijn and Jovanovic model does not provide any explanation for the 1987 stock market crash. As a final possibility, they consider whether the evolution of stock prices could be explained by the presence of a speculative bubble, "Is the stock market bubble-prone? Did a positive bubble burst, or a negative bubble form some time between 1968-1974? And today, do we see a positive bubble, especially in internet stocks?"

In this paper, we will examine the evolution of the S\&P 500 and its constituent sectors during the period January 1973 - June $2004^{6}$ in more detail in order to see whether the periodically collapsing speculative

\footnotetext{
${ }^{3}$ A model of technological growth that leads to booms and crashes, that allows for investor learning through the reduction of uncertainty about the limits of new technologies as these technologies become older, is presented in Jovanovic and Rob (1990). However, as uncertainty decreases in this model, so does the size of the 'bad' surprise in investor expectations.

${ }^{4}$ Hobijn and Jovanovic (2000) claim that the prices of firms in IT-intensive sectors should be better explained by the model and thus sectors with the highest IT investment after 1973 should experience the largest drops in value and then the largest increases. These sectors are Finance, Insurance and Real Estate, and the service sector in general.

${ }^{5}$ Hobijn and Jovanovic (2000) p. 29.

${ }^{6}$ We were only able to obtain sector data after January 1973 and thus we will restrict our analysis to this period. In addition, the definition of the GICS sectors changed substantially during our sample period and since the time elapsed
} 
bubble models can explain the apparent bubble deviations of actual prices from fundamental values. Furthermore, in order to examine whether all sectors within the S\&P 500 displayed bubble behavior during this period, we will estimate a speculative behavior model using sector data in an effort to see which sectors are responsible for the bubble like behavior of the aggregate S\&P 500. If we find that only the IT sector, or the high growth sectors in general, contain a speculative bubble, then this could imply that bubbles are a statistical artefact caused by the use of dividend-based fundamentals. ${ }^{7}$ If, however, we find that other sectors that could be valued more accurately using dividends also contain bubble deviations, this could be evidence that bubbles are endemic rather than being caused by the presence of bubbles in one or two fashionable sectors. To our knowledge, we are the first to test whether sector market prices contain bubbles and to see whether bubble-like behavior is present throughout the entire S\&P 500 Composite Index. In addition, we develop a joint model for cross-sectional contagion of bubbles across sectors and we examine whether there is evidence for bubble spillovers.

The rest of this paper is organized as follows: Section 2 describes the methodology used to construct the ten sector indices and provides descriptive statistics. Section 3 presents the bubble models that we employ, while Section 4 discusses the empirical results. Section 5 presents the multivariate bubble model and Section 6 provides some concluding remarks.

\section{Definitions and Discussion of the S\&P 500 and GICS sectors}

This paper employs data on the 10 S\&P 500 Global Industry Classification Standard (GICS) sector indices. The GICS is an industry classification system created by Standard \& Poor's in collaboration with Morgan Stanley Capital International that is used to classify firms into 10 sectors, 23 industry groups, 59 industries and 122 sub-industries according to their principal business activity. The sectors we examine are: Cyclical Services, Financials, Basic Industries, General Industrials, Cyclical Consumer Goods, IT, Non-Cyclical Consumer Goods, Non-cyclical Services, Resources, and Utilities. The indices that correspond to these sectors are calculated using the same principles as the S\&P 500 Composite Index. The appropriate series are then transformed into real series using the monthly CPI, and the implied cash dividends are obtained from the dividend yield, using the methodology described in Brooks and Katsaris (2005a). We obtain all our data from Datastream.

following the modification is insufficient for us to estimate the models, we are forced to restrict the sample period to end in 2004.

${ }^{7}$ The Information Technology sector is the only sector in which more than $50 \%$ of its member firms do not pay dividends. Note, however, that this percentage has decreased dramatically since the 1990s and that for all other sectors the percentage of dividend payers remains higher than $50 \%$. But in order for the results of our analysis to be directly comparable across sectors, we still construct dividend-based fundamentals for this one as well. 
We now examine the evolution of sector prices and implied dividends across time. As examples, in Figures 1 to 3 we present the monthly real GICS sector indices and the monthly real dividend yields for the Information Technology (IT), General Industrials and Resources sectors respectively. From Figure 1, we note that the IT Sector had only grown by around $40 \%$ until January 1996, yielding most of its extraordinary growth of $650 \%$ to the peak in the following five years of the sample before the equally spectacular collapse in value from April 2000. By contrast, the S\&P 500 Composite Index (not shown) had grown by just over $200 \%$ in the same period. Furthermore, from the graphs we can see that the dividend yields decreased to all time lows in 2000 before recovering only slightly by 2004 . Interestingly, the General Industrials sector (Figure 2) shows a remarkably similar pattern to the IT sector, although the price growth of the former is somewhat less spectacular than the latter. Thus many "old economy" sectors also appeared to show bubble-like growth in the 1990s. The only sector that does not exhibit such behavior in the slightest is Resources (Figure 3). In that case, the run up in prices is far less pronounced and there appeared to have been no substantial fall in valuations by the end of the sample period.

Other periods of very low dividend yields $(1929,1973$, and 1987) have been followed by significant corrections in S\&P 500 market values, and this fact can also be observed for the individual sectors. The General Industrials index has a very similar evolution to the S\&P 500 Composite, although it grows at a higher average rate, and the implied bubble deviations (see below) have a similar evolutionary pattern to the S\&P 500 Composite. Note that this sector has a stable participation in the S\&P 500 over the last 25 years that ranges between 10 and 15\%. When, however, we examine the Information Technology sector, we find that until 1995, this sector had a fairly constant participation in the S\&P 500, and the implied bubble deviations were fairly average in size. Nevertheless, after 1993 there is a persistent and increasing positive bubble deviation that reaches $90 \%$ before it begins to deflate, causing the IT index to lose around two thirds of its value.

As stated above, some critics may argue that the comparison of prices and dividends is not an effective measure of the relative performance for all sectors, especially for high technology sectors. For this reason, we also examine the evolution of prices relative to earnings-price ratios. ${ }^{8} \mathrm{We}$ find again that the earningsprice ratio is low prior to several corrections in prices, whereas it is quite high before significant market advances. Overall, in the last 10 years of our sample, the earnings-price ratios are quite low for most sectors and especially low for IT. Note that traditionally, high P/E ratios denote a market expectation of high future earnings growth. Therefore, we should expect that the E/P ratio for the high growth sectors in our sample should be lower than the E/P ratios of the Utilities and Materials sectors. However, several researchers and market practitioners argue that the evolution of prices in the 1990s resulted in unrealistically low E/P ratios

\footnotetext{
${ }^{8}$ Not shown due to space constraints but available from the authors on request.
} 
(high P/E ratios) in both technology and traditional sectors. For example, several dot.com companies had $\mathrm{P} / \mathrm{E}$ ratios larger than 1000 at the peak of the internet 'bubble'.

Overall, from the graphs, we note that the GICS sector indices display behavior that could be considered consistent with the existence of speculative bubbles. That is, an apparent under-valuation relative to dividends in the 1970s, an increasing over-valuation up until 1987, and an ever increasing overvaluation after that. However, some sector indices display significantly more variation around dividends than others. In the next sections, we will construct and describe the statistical properties of these bubble deviations and then test whether the evolution of market values of the 10 sectors is consistent with the presence of speculative bubbles.

\section{Models for Periodically Partially Collapsing Speculative Bubbles in Asset Prices}

Under the assumptions of rational expectations, risk-neutrality, constant discount rates and market equilibrium, the no arbitrage condition must hold and thus the price of a stock must be given by the present value of its future cash flows:

$p_{t}^{a}=\frac{E_{t}\left(p_{t+1}^{a}+d_{t+1}\right)}{(1+i)}$

In equation (1), $p_{t}^{a}$ is the actual price of the stock at time $t, d_{t}$ is the dividend paid by the stock in period $t$, $E_{t}($.$) is the mathematical expectations operator, and i$ is the constant expected real rate of return in equilibrium that is equal to the discount rate. ${ }^{9}$ Equation (1) shows that the actual price of a stock must be equal to the present value of the expected future price at which the security will be sold plus the expected dividend the investor will receive at time $t+1$.

If we allow for multi-period horizons, then equation (1) can be updated with the expectation of the price at $t+1$ and substituted into the original equation. Substituting recursively for all future prices in an infinite planning horizon and using the property of rational expectations that $E_{t}\left[E_{t+1}\left(\cdot_{t+2}\right)\right]=E_{t}\left({ }_{t+2}\right)$ will yield the fundamental value of a stock, $p_{t}^{f}$ :

$p_{t}^{f}=\sum_{g=1}^{\infty} \frac{1}{(1+i)^{g}} E_{t}\left(d_{t+g}\right)$

If we allow the actual market price of the stock to deviate from its fundamental value, the actual stock-price can be described by the relationship:

$p_{t}^{a}=p_{t}^{f}+b_{t}+u_{t}$

\footnotetext{
${ }^{9}$ Fama and French state that the expected or required return of an asset is the discount rate that relates a present value with its future cash flows (Fama and French (1988)).
} 
where $b_{t}$ is the bubble component at period $t$, and $u_{t}$ is a zero mean, constant variance error term that contains the unexpected innovation of both the bubble term and of the fundamental component. The bubble component $\left(b_{t}\right)$ is simply the difference between the actual price and the fundamental price of the security and is assumed here to have an evolutionary process that causes the systematic divergence of actual prices from their fundamental values.

Blanchard (1979), and Blanchard and Watson (1982) formulate a speculative bubble model in which the bubble component continues to grow with explosive expectations in the next time period with probability $q$, or crashes to zero with probability 1-q. If the bubble collapses, the actual price will be equal to the asset's fundamental value. In their model, the explosive behavior of bubble returns compensates the investor for the increased risk of a bubble crash as the bubble grows in size. However, according to this specification, if the bubble term in period $t+1$ crashes to zero then it cannot regenerate since the expected bubble is equal to zero. This implies that there can be only one observed bubble in any financial time series (Diba and Grossman (1988a)). Furthermore, the model requires the assumption that the bubble crashes immediately to its collapsing state value. These are restrictive assumptions, since it is plausible that there could be several bubble episodes in a financial time series or that a bubble could slowly deflate for several time periods. In 1929 and 1987, the market peaked in late August and crashed in October whereas the strong correction in the Tokyo Stock Exchange took several months after January 1990. Moreover, the explosive nature of bubbles leads Diba and Grossman (1988b) to conclude that under rational expectations, negative bubbles cannot exist since investors cannot rationally expect the value of a stock to become negative in finite time. This arises since if a negative rational speculative bubble exists, the bubble will grow geometrically causing the stock price to decrease without bound and become negative in finite time.

In order to lift the requirement for these unrealistic restrictions, van Norden and Shaller (hereafter vNS, 1993 ) formulate a periodically partially collapsing, positive and negative speculative bubble model that has a time varying probability of collapse. Brooks and Katsaris (2005b) propose an extension of their model to incorporate a measure of abnormal volume in the equations for returns in the surviving regime and in the probability of bubble collapse. Their model may be expressed as:

$$
\frac{(1+i) b_{t}}{q\left(B_{t}, V_{t}^{x}\right)}-\frac{1-q\left(B_{t}, V_{t}^{x}\right)}{q\left(B_{t}, V_{t}^{x}\right)} u\left(B_{t}\right) p_{t}^{a} \quad \text { with probability } q\left(B_{t}, V_{t}^{x}\right)
$$

$E_{t}\left(b_{t+1}\right)=$

$$
u\left(B_{t}\right) p_{t}^{a} \quad \text { with probability } 1-q\left(B_{t}, V_{t}^{x}\right)
$$

In (4), $q\left(B_{t}, V_{t}^{x}\right)$ is the probability of the bubble continuing to exist that is a function of the relative absolute size of the bubble and the measure of abnormal volume where $\partial q\left(B_{t}, V_{t}^{x}\right) / \partial\left|B_{t}\right|<0$ and 
$\partial q\left(B_{t}, V_{t}^{x}\right) / \partial V_{t}^{x}<0$, and $V_{t}^{x}$ is a measure of unusual volume in period $t$. Following vNS, in equation (4) the expected size of the bubble is a function of the probability of a crash, the size of the bubble at period $t$ and the function $u\left(B_{t}\right)$, which is the relative size of the bubble in the collapsing state. The probability of the bubble continuing to exist is a negative function of the absolute (since we allow negative bubbles to exist) size of the bubble, and the measure of abnormal volume. From (4) we can derive the gross returns on the stock when a bubble is present under the assumption that dividends follow a geometric random walk with a constant drift. ${ }^{10}$ Under this assumption, we can show that the expected next period gross returns are given by:

$$
\begin{aligned}
& E_{t}\left(r_{t+1} \mid W_{t+1}=S\right)=\left[M\left(1-B_{t}\right)+\frac{M}{q\left(B_{t}, V_{t}^{x}\right)} B_{t}-\frac{1-q\left(B_{t}, V_{t}^{x}\right)}{q\left(B_{t}, V_{t}^{x}\right)} u\left(B_{t}\right)\right] \\
& E_{t}\left(r_{t+1} \mid W_{t+1}=C\right)=\left[M\left(1-B_{t}\right)+u\left(B_{t}\right)\right] \\
& P\left(W_{t+1}=S\right)=q\left(B_{t}, V_{t}^{x}\right)=\Omega\left(\beta_{q, 0}+\beta_{q, b}\left|B_{t}\right|+\gamma_{q, V} V_{t}^{x}\right)
\end{aligned}
$$

where $r_{t+1}$ denotes the gross return of period $t+1$ conditioning the state at time $t+1$ being the surviving $(S)$ or collapsing $(C)$ state and on all other information at time $t, \gamma_{q, V}$ is the sensitivity of the probability of survival to the measure of abnormal volume, $M$ is the gross fundamental return on the security and $\Omega$ is the standard normal cumulative density function. Note that the measure of abnormal volume affects the expected returns on the asset only indirectly through the probability of the process being in state $S$ or $C$ in period $t+1$. Abnormal volume is thus suggested to signal an increase in the size of the tail of the distribution of expected returns that would signify a collapse of the bubble. We follow vNS and select a probit model for the probability of survival $\left(P\left(W_{t+1}=S\right)\right)$ since it satisfies the conditions set above and it ensures that probability estimates are bounded between zero and one. Furthermore, it should be noted that equations (5) through (7) satisfy the no-arbitrage condition since the ex ante expected gross return on the bubbly asset is equal to the expected gross return on the bubble-free asset $(M)$ and therefore it is rational for a risk-neutral investor to hold the bubbly asset. The realized return if the bubble survives is greater than the required gross return $(M)$, whereas if the bubble collapses it yields negative actual returns (positive in the case of a negative bubble).

Equations (5)-(7) are non-linear and so for estimation they are linearized by taking the first order Taylor series approximation around an arbitrary $B_{0}$ and $V_{0}{ }^{x}$ to arrive at a linear switching regression model:

$$
\begin{aligned}
& r_{t+1}=\beta_{S, 0}+\beta_{S, b} B_{t}+\beta_{S, V} V_{t}^{x}+u_{t+1}^{S} \\
& r_{t+1}=\beta_{C, 0}+\beta_{C, b} B_{t}+u_{t+1}^{C}
\end{aligned}
$$

\footnotetext{
${ }^{10}$ This is a common assumption in the literature; see for example Fama and French (1988), Kleidon (1986a).
} 
$P\left(W_{t+1}=S\right)=q\left(B_{t}, V_{t}^{x}\right)=\Omega\left(\beta_{q, 0}+\beta_{q, b}\left|B_{t}\right|+\gamma_{q, V} V_{t}^{x}\right)$

where $u_{t+1}^{S}$ is the unexpected gross return in the surviving regime and $u_{t+1}^{C}$ is the unexpected gross return in the collapsing regime.

Equation (8) states that the returns in the surviving regime are a function of the relative size of the bubble and of the measure of abnormal volume. In effect, equation (8) implies that as the bubble grows, investors demand higher returns in order to compensate them for the probability of a bubble collapse and since abnormal volume signals a possible change in the long run trend in equity prices, investors want to be compensated for this risk as well. The above linear switching regression model has a single stateindependent probability of switching regimes $P\left(r_{t+1} \mid S\right)$ that is a function of the relative size of the bubble and of the measure of abnormal volume. We estimate the augmented model under the assumption of disturbance normality using maximum likelihood. ${ }^{11}$

From the first order Taylor series expansion, we can derive certain conditions that must hold if the periodically collapsing speculative bubble model has explanatory power for stock market returns. If the above model can explain the variation in future returns, then this would be evidence in favor of the presence of periodically collapsing speculative bubbles in the data. These restrictions are:

$$
\begin{aligned}
& \beta_{S, 0} \neq \beta_{C, 0} \\
& \beta_{C, b}<0 \\
& \beta_{S, b}>\beta_{C, b} \\
& \beta_{q, b}<0 \\
& \gamma_{q, V}<0 \\
& \beta_{S, V}>0
\end{aligned}
$$

Restriction (a) implies that the mean return across the two regimes is different, so that there exist two distinct regimes, although we cannot say anything about the relative size of these coefficients. Restriction (b) implies that the expected return should be negative if the collapsing regime is observed. This means that the bubble must be smaller in the following period if the bubble collapses. Note that the opposite holds for negative bubbles: the larger the negative bubble, the more positive the returns in the collapsing regime. Restriction (c) ensures that the bubble yields higher (lower) returns if a positive (negative) bubble is observed in the surviving regime than in the collapsing regime. Restriction (d) must hold since the probability of the bubble continuing to exist is expected to decrease as the size of the bubble increases.

\footnotetext{
${ }^{11}$ Full details of the estimation procedure are presented in Brooks and Katsaris (2005a).
} 
Restrictions (a) to (d) are equivalent to the restrictions derived by vNS. The additional restriction (e) must hold so that abnormally high volume signals an imminent collapse of the bubble. Finally, restriction (f) states that the coefficient on the abnormal volume measure in the state equation must be greater than zero since, as volume increases, investors perceive an increase in market risk.

We examine the power of the model to capture bubble effects in the returns of the S\&P 500 and its sectors by testing the model against three simpler specifications that capture stylized features of stock market returns. These models are nested within the speculative bubble model. Firstly, we examine whether the effects captured by the switching model can be explained by a more parsimonious model of changing volatility. In order to test this alternative, we follow vNS and jointly impose the following restrictions:

$$
\begin{aligned}
& \beta_{C, 0}=\beta_{S, 0} \\
& \beta_{S, b}=\beta_{C, b}=\beta_{S, V}=\beta_{q, b}=\gamma_{q, V}=0 \\
& \sigma_{S} \neq \sigma_{C}
\end{aligned}
$$

Restriction (11.1) implies that the mean return across the two regimes is the same and restriction (11.2) states the bubble deviation has no explanatory power for next period returns or for the probability of switching regimes. The later point suggests that there is a constant probability of switching between a high variance and low variance regime as this is stated in restriction (11.3).

In order to separate restrictions (11.1) and (11.2), we examine whether returns can be characterized by a simple mixture of normal distributions model, which only allows mean returns and variances to differ across the two regimes. This mixture of normal distributions model implies the following restrictions:

$$
\beta_{S, b}=\beta_{C, b}=\beta_{S, V}=\beta_{q, b}=\gamma_{q, V}=0
$$

Another possible alternative is that of mean reversion in prices (fads) as described by Cutler et al. (1991). Under the fads model, returns are linearly predictable although mean returns do not differ across regimes. Furthermore, the deviation of actual prices from the fundamentals has no predictive ability for the probability of switching regimes. The returns in the two regimes are characterized by different variances of residuals but are the same linear functions of bubble deviations. The fads model is thus:

$$
\begin{aligned}
& r_{t+1}^{S}=\beta_{0}+\beta_{b} B_{t}+u_{S, t+1} \\
& r_{t+1}^{C}=\beta_{0}+\beta_{b} B_{t}+u_{C, t+1} \\
& q_{t}=\Omega\left(\beta_{q, 0}\right)
\end{aligned}
$$

In the above equations, $u_{t+1} \sim N\left(0, \sigma_{S}\right)$ with probability $q_{t}, u_{t+1} \sim N\left(0, \sigma_{C}\right)$ with probability $1-q_{t}$.

\section{Measures of Fundamental Values}

A number of methods for constructing measures of fundamental values can be found in the literature, 
including approaches based on dividend multiple measures, or based on an augmented Gordon growth model. The Campbell and Shiller (1987) methodology can allow for predictable time-variation in the growth rate of dividends, although the approach assumes that both the actual spread and the dividend growth rate are stationary. However, if the actual spread is not stationary, this may lead to spurious regression problems and inefficient forecasts of the theoretical spread for those sectors. We therefore adopt the dividend multiple measure of fundamentals employed by van Norden and Schaller (1999). ${ }^{12}$ Before describing this approach, we should state that we recognize the limitations of using dividend-based fundamentals to value high growth sectors such as Information Technology. It is a common view that such high growth sectors should not be valued according to tangible assets or balance sheets since most of the value added in such sectors originates from 'soft' variables, such as intellectual human capital, patents, strategic alliances, joint ventures, market share, and in the case of internet companies, other variables such as web traffic and number of unique visitors (see, for example, Rajgopal, Kotha and Venkatchalam (2000)). Nevertheless, Damodaran (2000) and Hand and Landsman (1999) argue and empirically show that the fundamentals of equity valuation still apply to high technology firms and that classic accounting variables are relevant in the pricing of such stocks. However, such valuations are very noisy and other 'soft' variables often complement high technology stock valuations.

vNS (1999) show that if the discount rate is constant, then stock market prices follow the period-by-period arbitrage condition given by equation (1). Assuming that dividends follow a geometric random walk, i.e. that log dividends follow a random walk with a drift, it can be shown that the fundamental price of a stock will be equal to a multiple of current dividends:

$p_{t}^{f}=\rho d_{t}$

where $\rho=\frac{1+r}{e^{\left(a+\frac{\sigma^{2}}{2}\right)}-1}$. We use the sample mean of the price-dividend ratio to approximate $\rho$. In this setting, the relative bubble size is given by:

$B_{t}=\frac{b_{t}}{p_{t}}=\frac{p_{t}-p_{t}^{f}}{p_{t}}=1-\frac{\rho d_{t}}{p_{t}}$

\section{Empirical Evidence}

In this Section we will present the results of the models presented above for the S\&P 500 Composite and the 10 GICS sector indices. The models we estimate are the original van Norden and Schaller model, and

\footnotetext{
${ }^{12}$ However, for the Cyclical Services, Financials, General Industrials, Cyclical Consumer Goods, IT and NonCyclical Services sectors, the Campbell and Shiller methodology produces more robust results and so the results from their approach are presented for those sectors.
} 
the augmented model that contains volume as a predictor and classifier of returns. ${ }^{13}$ In order to test for the no-bubble hypothesis, we perform likelihood ratio tests for the implied model restrictions on the coefficient estimates, and in order to ensure that we are not misinterpreting stylized facts about stock market returns such as volatility regimes, mixtures of normals and mean reversion as evidence in favor of bubbles, we use likelihood ratio tests in order to statistically verify that we are capturing more of the variability of returns than these simpler alternatives.

In Table 1, we present the results for the S\&P 500 Composite index and each of the sectors for the augmented vNS model using the dividend multiple measure of fundamental values for the period January 1973 - June 2004. The first panel of the table contains the coefficient estimates for the nine models, the loglikelihood function values at the optimum, and the three information criteria. The second panel contains the results of the likelihood ratio tests for the speculative behavior coefficient restrictions. Finally, the last panel of the table contains the LR test results of the alternative model specifications. Therefore, we test whether a mixture of normals can explain returns better than a simple volatility regimes model, and in turn whether a fads model captures any additional characteristics in the data.

From the results, we can see that for the S\&P 500 as a whole, the null hypothesis of no-bubbles can be rejected since most of the speculative behavior models' restrictions are satisfied by the data (i.e. their respective nulls are rejected in favor of bubble behavior). Specifically, the bubble deviation is significant in predicting the levels and the generating state of returns (since $\beta_{S, B}$ and $\beta_{q, B}$ are both statistically significant respectively), and as the bubble grows, the returns in the surviving regime become increasingly higher (when a positive bubble is present) whereas the returns in the collapsing regime are a negative function of the bubble size (since $\beta_{C, B}$ is negative). As the bubble grows, the probability of being in the surviving explosive regime $(S)$ decreases and the expected return in the collapsing state becomes even smaller (when a positive bubble is present). Furthermore, the model identifies two distinct regimes of stock market returns: one in which small positive returns with small variance $\left(\sigma_{S}\right)$ are observed and one in which returns are large and negative and have large variance $\left(\sigma_{C}\right)$. The coefficient estimates appear to be consistent with the periodically collapsing speculative bubbles model, and it appears that the augmented model can capture an additional proportion of the variability of returns when we compare it to the three stylized alternatives of volatility regimes, fads and mixture of normals (although the latter test statistic is not quite statistically significant). Overall, there is a very small probability of being in the collapsing regime $\left(\beta_{q, 0}\right)$ when the bubble size is zero and volume is normal. Nevertheless, as the bubble increases, this probability increases dramatically. From the above, we can conclude that the divergence of the S\&P 500 from the dividend multiple fundamental values can be considered the result of speculative behavior. Therefore, the Hobijn and

\footnotetext{
${ }^{13}$ In the interests of brevity, only the results from the augmented model are presented.
} 
Jovanovic (2000) assertion that a bubble would not be able to explain the evolution of the S\&P 500 in the last 25 years is not supported.

Turning our attention to the sector indices, overall, the results are indicative of the presence of bubbles in several of the sectors, namely Financials, General Industrials, Information Technology and Non-Cyclical Services. There is also some evidence in favor of periodic, partially collapsing speculative bubbles in the Cyclical Services, Basic Industries and Utilities sectors. This leaves only three sectors for which there is virtually no evidence for bubble-like behavior. Let us now consider these results in greater detail.

When we examine the Financials index, the collapsing explosive regime has a significantly lower average probability of occurring. Nevertheless, as the bubble grows, the probability of observing the collapsing regime increases dramatically since, if the measure of abnormal volume and the spread of actual returns are equal to zero, when the bubble size is equal to $50 \%$, the probability of observing the collapsing regime is close to 50\%. More importantly, all the coefficients have the right signs and are significantly different from zero, and the LR test results imply that the augmented model captures additional information contained in the index returns, so that the volatility regimes, mixture of normals and fads specifications are all rejected.

Considering now the Resources index, a sector that is commonly considered to contain a bubble in the early 1980s, the bubble deviations in the surviving state equation are statistically insignificant and not all of the theoretical restrictions are satisfied by the data, although all of the coefficient signs and magnitudes are correct. From the estimates of the model, we calculate that the probability of the next period returns being generated by the collapsing state in January 1982 was over 50\%, a value much higher than it had taken previously during our sample period. The index lost $13 \%$ in February 1982, which provides anecdotal evidence that the speculative behavior model could potentially be used to predict the level and the generating state of returns.

The same conclusions can be drawn if we examine the General Industrials and the Non-Cyclical Services sectors, since the information criteria indicate that the augmented speculative behavior model can better capture the variability of returns than alternative specifications. Furthermore, the coefficients in the state and classifying equations are significantly different from zero and have the correct sign, and the LR tests again reject the more parsimonious alternatives (in the latter case).

Let us now examine the Information Technology sector. As noted earlier, this index experiences the largest increase over the sample period and contains the largest bubble deviation. All of the speculative behavior model coefficients have the correct sign and are statistically significant. Note that when the bubble deviation and the measure of abnormal volume are equal to zero, the probability of observing the collapsing regime is small although larger than for any other sector. But the responsiveness of the probability of being 
in the collapsing regime to a growth in the size of the bubble is relatively modest. So it would take a bubble size in excess of $50 \%$ for the probability of the bubble surviving to fall below $50 \%$. This result can be attributed to the fact that the estimated bubble deviation was extremely large in the 1990s but continued to grow even larger before eventually bursting.

Turning now to the Resources and the Utilities sectors, we find that, contrary to common opinion that the Resources index contained a bubble in the early 1980s, this index is better explained by a simple volatility regimes model. However, we note that the speculative models' coefficients are mostly still significant, and all have the expected signs. Similarly, when we examine the Utilities sector results, we find that the mixture of normals or fads models are able to capture the characteristics of returns better than any of the more complex specifications. This result is perhaps expected since this sector contains "old economy" stocks and the actual index varies around its fundamental values, so that the bubble deviations do not expand or collapse abruptly and thus there is only limited evidence for bubble-like behavior. ${ }^{14}$

From the above, we can conclude that the bubble deviations of the S\&P 500 from its dividend based fundamental values are a result of the deviation of not only the Information Technology sector but of the deviations of other, more traditional sectors from their fundamental values. This finding is in contrast to Hobijn and Jovanovic's (2000) claim that the undervaluation of the 1970s can mainly be attributed to the Financials and the IT sectors. However, their model suggests that these sectors and the services sector in general should experience the highest growth in the 1980s and 1990s because of the listing on the stock market of new, high growth firms that contain a large share of the claim to future dividends. Unfortunately, we do not have the data to examine this hypothesis directly.

If we now turn our attention to the 1990s, several sectors - namely the Cyclical Services, Non-Cyclical Services, Resources, General Industrials, Cyclical Consumer Goods, Non-Cyclical Consumer Goods and Information Technology indices - were overvalued by at least 30\% in January 1996. These sectors represented more than $60 \%$ of the S\&P 500 Composite index, which was overvalued in the same period by almost $40 \%$. More importantly, we note that in January 2000, the estimated bubble deviation of the Composite index was $60 \%$. One point worth noting is that after March 2000, when the bubble deviations in the aforementioned sectors began to deflate, sectors that were overvalued by less than $40 \%$ relative to the dividend multiple fundamental values in January 2000 (namely the Utilities, Financials and Basic Industries indices) experienced a relatively significant increase in their bubble deviations until the end of our sample period. These sectors accounted for around a quarter of the total capitalization of the Composite index in

\footnotetext{
${ }^{14}$ We also estimated all of the models using the Campbell and Shiller measure of fundamental values in order to examine the robustness of our results against fundamentals that allow for predictable variation in the dividend growth rate. These results are not presented here for brevity but can be obtained from the authors on request and are qualitatively identical to the results for the dividend multiple fundamental values.
} 
January 2000, and by January 2001 their share had grown to over $30 \%$. This could be taken as evidence that once investors realized that the bubble deviation was bursting, they shifted funds to relatively "safe" sectors with a smaller risk of observing a bubble collapse.

\section{Bubble Spillovers between Sectors}

Even a casual examination of Figures 1 to 3 reveals some divergence between the sectors in terms of when the fast growth phase of the bubble started and when the price index hit its peak. For example, the Basic Industries sector arguably started its strongest expansion phase in March 1995; it began its collapse in May 1999 and then started to recover by October 2000 although it remained volatile. While General Industrials started its ascent at around the same time, the reversal in this case did not take place until September 2000. Similarly, the Information Technology sector, widely attributed as being the root of the tech bubble, showed no signs of slowdown until September 2000, more than a year after Basic Industries but a month before Utilities. The Resources sector grew fairly rapidly from February 1995 and became volatile from May 1998 although it largely avoided a full-scale collapse. The downfall in Financials did not start until February 2001 although it had fully recovered by April 2004. These anecdotal observations suggest that, contrary to popular opinion, even if the formation of the tech bubble can be attributed to Technology, Telecommunications and the Media, the subsequent collapse started with faltering prices in more conventional sectors that one might expect to be affected at the early stages of an impending economic slowdown (Basic Industries and Resources). This motivates us to examine whether a bubble that is present in one sector may subsequently spread to other sectors.

We now proceed to build an empirical model that can allow for spillovers in both the levels of returns in the sectors and in the generating equations. While there is potentially a large number of ways that this could be achieved, we focus on a natural extension of the models that were described in Section 3. We also rule out contemporaneous spillovers between sectors, allowing only for lagged effects. Not only is this in the spirit of reduced form VAR modeling, but more importantly, it ensures that the equations do not suffer from under-identification. We let the returns in the surviving regime (equation (8)) depend on the lagged size of the bubble in all sectors (not just the lagged bubble size in that sector as was the case above) and on the lagged abnormal volume in all sectors; likewise, the return in the collapsing regime also depends on the one period lagged value of the size of the bubble in all sectors. The probability of being in the surviving regime will also be dependent upon the bubble sizes and volumes in all sectors:

$$
\begin{aligned}
& r_{t+1}=\beta_{S, 0}+\sum_{j=1}^{10} \beta_{S, b, j} B_{t, j}+\sum_{j=1}^{10} \beta_{S, V, j} V_{t, j}^{x}+u_{t+1}^{S} \\
& r_{t+1}=\beta_{C, 0}+\sum_{j=1}^{10} \beta_{C, b, j} B_{t, j}+u_{t+1}^{C}
\end{aligned}
$$




$$
P\left(W_{t+1}=S\right)=q\left(B_{t, j}, V_{t, j}^{x}\right)=\Omega\left(\beta_{q, 0}+\sum_{j=1}^{10} \beta_{q, b, j}\left|B_{t, j}\right|+\sum_{j=1}^{10} \gamma_{q, V, j} V_{t, j}^{x}\right)
$$

where all notation is as above and the additional $j$ subscript denotes each individual sector. The likelihood function used to estimate such a model will still have the same "shape" as for the analysis of each separate sector, but it will now be extended in the same spirit as the return equations:

$$
\ell\left(r_{t+1} \mid \xi\right)=\sum_{t=1}^{T} \ln \left[P\left(W_{t+1}=S\right) \frac{\left(\frac{r_{t+1}-\beta_{S, 0}-\sum_{j=1}^{10} \beta_{S, b, j} B_{t, j}-\sum_{j=1}^{10} \beta_{S, V, j} V_{t, j}^{x}}{\sigma_{S}}\right)}{\sigma_{S}}+P\left(W_{t+1}=C\right) \frac{\omega\left(\frac{r_{t+1}-\beta_{C, 0}-\sum_{j=1}^{10} \beta_{C, b, j} B_{t, j}}{\sigma_{C}}\right)}{\sigma_{C}}\right]
$$

The approach defined by equations $\left(8^{\prime}\right)-\left(10^{\prime}\right)$ and (16) must be estimated ten times - one for each sector. For each of these ten models, the dependent variable would be different but the independent variables would be exactly the same. This model is likely to be tricky to estimate given that it contains a total of 55 parameters. There are a number of ways we could simplify it, and some obvious possibilities are:

1. Remove abnormal volume from the surviving regime equation $\left(8^{\prime}\right)$ (and thus also in equation (16)).

2. Remove abnormal volume from the state-determining equation $\left(10^{\prime}\right)$.

3. Remove volume from both $\left(8^{\prime}\right)$ and $\left(10^{\prime}\right)$.

4. Make the model dependent on the bubble in the sector under consideration and in the market as a whole rather than all the other sectors. Equations $\left(8^{\prime}\right)$ to $\left(10^{\prime}\right)$ would thus become

$$
\begin{aligned}
& r_{t+1}=\beta_{S, 0}+\beta_{S, b} B_{t}+\beta_{S, V} V_{t}^{x}+\beta_{S, b, I} B_{t, I}+\beta_{S, V, I} V_{t, I}^{x}+u_{t+1}^{S} \\
& r_{t+1}=\beta_{C, 0}+\beta_{C, b} B_{t}+\beta_{C, b, I} B_{t, I}+u_{t+1}^{C} \\
& P\left(W_{t+1}=S\right)=q\left(B_{t}, V_{t}^{x}\right)=\Omega\left(\beta_{q, 0}+\beta_{q, b}\left|B_{t}\right|+\gamma_{q, V} V_{t}^{x}+\beta_{q, b, I}\left|B_{t, I}\right|+\gamma_{q, V, I} V_{t, I}^{x}\right) \\
& \ell\left(r_{t+1} \mid \xi\right)=\sum_{t=1}^{T} \ln \left[P\left(W_{t+1}=S\right) \frac{\omega\left(\frac{r_{r+1}-\beta_{S, 0}-\beta_{S, b} B_{t}-\beta_{S, V} V_{t}^{x}}{\sigma_{S}}\right)}{\sigma_{S}}+P\left(W_{t+1}=C\right) \frac{\omega\left(\frac{r_{t+1}-\beta_{C, 0}-\beta_{C, b} B_{t}}{\sigma_{C}}\right)}{\sigma_{C}}\right]
\end{aligned}
$$

where the additional subscript $I$ denotes the stock index for the whole market.

In order to avoid the inclusion of an excessive number of tables, we only report the results for the model corresponding to restriction 4 and the unrestricted case in Tables 2 and 3 respectively. It is clear from Table 2 that both the levels equations and the probabilities of bubble collapse in a number of individual sectors 
respond to the size of the bubble in the market as a whole as well as that in their own sector, and most of the additional parameters are statistically significant for the Cyclical Services, Information Technology, NonCyclical Services, Resources and Utilities sectors. For example, in the case of the resources sector, the return in the surviving regime is a positive and significant function $\left(\beta_{S, B, I}\right)$ of the market-wide bubble deviation, while for the return in the collapsing regime $\left(\beta_{C, B, I}\right)$, it is negative as expected, albeit not significantly so. The probability of being in the surviving regime is, as expected, a negative and highly significant function of the size of the market bubble. The second panel of Table 2 reports the likelihood ratio test statistics for restrictions of the model to several simpler alternatives as discussed above. In addition, the final row tests the null hypothesis that the lagged market-wide bubble size and volume terms are not statistically significant. The latter restriction is clearly rejected for nine of the ten sectors, indicating that not only sector-specific changes in the size of the bubble and of abnormal volume but also market-wide influences are important determinants of subsequent bubble behavior at the sector level.

In order to determine more specifically whether the bubble-like behavior in the sectors and the market as a whole emanate from a small number of specific industries, Table 3 reports the analysis for the unrestricted model where the next period returns are a function of the current size of the bubble and of abnormal volume not only in that sector but also in all of the other sectors. The table is organized so that each column represents estimation for the next period returns to the sector given by the column header, with the blocks of rows representing the lagged variables. Thus the parameter estimates corresponding to the own lags are on the leading diagonal.

Table 3 shows that the expected returns in the surviving and collapsing regimes and the probability of the bubble surviving respond to a much greater extent to the lagged bubble sizes and lagged volumes in some sectors than others. Notably, Cyclical Services, Financials, Basic Industries and General Industries seem to be highly responsive while Non-Cyclical Consumer Goods and Utilities appear to be relatively isolated. Perhaps more importantly, in terms of the statistical significance of the parameter estimates, it appears that the bubbles in the Basic Industries, Cyclical Consumer Goods, Information Technology and Resources sectors are particularly contagious from the perspective that the bubbles in these sectors influence the levels and probability of collapse of a considerable number of other sectors. For example, the size of the bubble in the IT sector affects either the size of the return in the surviving or collapsing regime or the probability of the bubble surviving for the Cyclical Services, Financials, Basic Industries, General Industrials, Cyclical Consumer Goods, Non-Cyclical Services and Resources sectors. On the other hand, bubbles specific to the Utilities and Non-Cyclical Services sectors, for instance, have very limited spillovers to other industries. Although the very large number of parameters involved in this model makes interpretation a difficult task, the most salient feature is that bubble transmission at the sector level is multi-directional and did not originate purely from Information Technology and related industries. 
The final panel of Table 3 shows likelihood ratio tests of restrictions of the general model that incorporates lagged influences from all other sectors to five simpler alternatives. The last two of these restrictions are to the augmented model with no spillovers and to the augmented model with market-wide bubble size and volume terms respectively. The results show that the model with spillovers is preferred to the univariate augmented model for all ten sectors, although it is preferred to the much more parsimonious model with market-wide terms for only four of them at the 5\% significance level (Basic Industries, Cyclical Consumer Goods, Financials and Resources).

\section{Conclusions}

In this paper, we examined the presence of periodically collapsing speculative bubbles in the S\&P 500 and its constituent sectors. Market practitioners and academic researchers have suggested that the Information Technology and Resources sectors were significantly affected by speculative bubbles in the last 25 years, but by implication, that other sectors remained bubble-free. To our knowledge, we are the first directly to test for the presence of bubbles in specific stock market sectors, and we believe that our findings shed light on the behavior of these sector indices.

We employ data for the 10 GICS sectors for the period January 1973 - June 2004. These indices represent the ten major economic sectors of the member firms (Cyclical Services, Financials, Basic Industries, General Industrials, Cyclical Consumer Goods, IT, Non-Cyclical Consumer Goods, Non-cyclical Services, Resources, and Utilities). Using a fundamental measure based on dividend-multiples, we estimate two speculative behavior models: a model by van Norden and Schaller (1997), and an augmented model proposed by Brooks and Katsaris (2005b). Furthermore, we estimate five alternative models that capture stylized facts about securities returns and that are nested within the speculative behavior models. This is done in order to test whether the speculative behavior models capture any additional information about the variation of returns.

From the results, we can conclude that the augmented speculative behavior model has superior explanatory power to all of the alternative models for 4 out of 10 sectors. Thus, for the sample examined, the S\&P 500 Composite and these 4 sectors appear to contain a bubble. The bubbly sectors are Financials, Information Technology, General Industrials and Non-Cyclical Services. There is also some evidence of bubble-like behavior in 3 other sectors. In most cases, we found that the size of the bubble deviation and the measure of abnormal volume are significant predictors of returns. Although the relationships between the probabilities of being in a particular regime and the size of the bubble, the measure of abnormal volume and the spread of actual returns vary considerably across sectors, for all sectors, the probability of observing the collapsing regime is positively related to the absolute bubble size and the measure of abnormal volume. We find that the probability of the bubble continuing to exist decreases dramatically for large bubble sizes and abnormal 
volume realizations. Even though the augmented model yields a large and persistent probability of the collapsing regime for five years of the sample without a crash actually occurring, in 2000 the IT index lost $50 \%$ of its value, and by August 2002, the IT index was down $80 \%$ from its all time high. Note that the estimated bubble deviation when the IT index peaked in March 2000 was 91\%. This could be evidence that investors have now driven prices in this index back towards its dividend-based fundamentals.

We show that a mixture of normals and a fads model better explain the Resources and the Utilities indices respectively than a speculative bubble model. Although some practitioners claim that a bubble was formed in the early 1980s in the global basic materials sector, we find no evidence that the perceived bubble deviations displayed periodically collapsing speculative bubble behavior during our sample period since the size of the bubble is unable significantly to predict the level or the generating state of returns.

One particularly interesting observation is that towards the end of our sample after the IT bubble had begun to deflate, there is an increase in the deviations of actual prices from fundamental values in the four sectors with the lowest bubble deviations in March 2000. These sectors were Non-Cyclical Consumer Goods, Financials, Resources and Utilities. This could be taken as evidence that investors shifted their capital to sectors with a smaller probability of a bubble collapse, since very few investors would completely liquidate their holdings in the S\&P 500. This could also be thought of as suggesting that market participants were aware that some sectors had a smaller bubble deviation than others, and were thus less at risk from the bubble bursting in 2000 and 2001.

We additionally propose and implement an approach that can allow for contagion in bubbles between one sector and another. Since such models are highly parameter-intensive, we demonstrate several ways in which they can be simplified. The results show that bubble-transmission over our sample period arose from several sectors including Cyclical Consumer Goods and Basic Industries and not just from IT as popular opinion might suggest.

To summarize, our central conclusion is that bubble-like behavior is not confined to a small segment of the stock market, but appears to be present in more than $70 \%$ of it. A key implication of this result is that if market participants believe dividend-based fundamental measures not to be appropriate for valuing the technology stocks, they are equally inappropriate for companies in other, more conventional, sectors and for the market as a whole.

This research suggests several potentially useful lines of further research enquiry. First, it ought to be worthwhile to consider further refinements to the bubble spillovers model so that it might be parameterized more parsimoniously. For example, an approach based on principal components could be used to reduce the dimensionality of the system. Second, from an asset allocation perspective, it would be of interest to 
determine whether approaches based on estimating separate bubble models for each sector could be used to time the market. A trading rule so-formed would buy into sectors where a bubble was in the early stages of growing and would switch into less bubbly sectors when the probability of bubble collapse became unacceptably high. Brunnermeier and Nagel (2004) suggest that hedge funds were implicitly able to do this in the context of the recent rise and fall of the technology sector. 


\section{References}

Blanchard, O. J. 1979. Speculative Bubbles, Crashes and Rational Expectations. Economics Letters. 3 no. 4: $387-389$.

Blanchard, O. J., and Watson, M. W. 1982. Bubbles, Rational Expectations and Financial Markets. NBER Working Paper no. 945. Cambridge, Mass.: National Bureau of Economic Research.

Bohl, M. T. 2000. Periodically Collapsing Bubbles in the US Stock Market. Working Paper, Department of Economics, European University: Viadrina Frankfurt (Oder).

Brooks, C. and Katsaris, A. 2005a. A Three-Regime Model of Speculative Behavior: Modelling the Evolution of Bubbles in the S\&P 500 Composite Index Economic Journal 115(505), 767-797

Brooks, C. and Katsaris, A. 2005b. Trading Rules from Forecasting the Collapse of Speculative Bubbles for the S\&P 500 Composite Index Journal of Business 78(5), 2003-2036

Brunnermeier, M.K. and Nagel, S. 2004. Hedge Funds and the Technology Bubble Journal of Finance 59, $2013-2040$.

Campbell, J. Y., and Shiller, R. 1987. Cointegration and Tests of Present Value Models. Journal of Political Economy. 95 (October): 1062-1088.

Cutler, D. M.; Poterba, J. M.; and Summers, L. H. 1991. Speculative Dynamics. Review of Economic Studies. 58 (May): 529-546.

Damodaran, A. 2000. The Dark Side of Valuation: Firms with no Earnings, no History and no Comparables: Can Amazon.com be Valued? Working paper, Stern School of Business.

Dezhbakhsh, H., and Demirguc-Kunt, A. 1990. On the presence of Speculative Bubbles in Stock Prices. Journal of Financial and Quantitative Analysis. 25 (March): 101-112.

Diba, B. T., and Grossman, H. I. 1988a. Explosive Rational Bubbles in Stock Prices? American Economic Review. 78 (June): 520-530.

Diba, B. T., and Grossman, H. I. 1988b. The Theory of Rational Bubbles in Stock Prices. Economic Journal. 98 (September): 746-754.

Evans, G. W. 1991. Pitfalls in Testing for Explosive Bubbles in Asset Prices. American Economic Review. 81 (September): 922-930.

Fama, F. E., and French, K. R. 1988. Permanent and Temporary Components of Stock Prices. Journal of Political Economy. 96 (April): 246-273.

Flood, R. P., and Garber, P. 1980. Market Fundamentals Versus Price Level Bubbles: The first Tests. Journal of Political Economy. 88 (August): 745-770.

Goldfeld, S. M., and Quandt, R. E. 1976. Studies in Nonlinear Estimation. Cambridge, Ballinger.

Greenwood J. and Jovanovic B., 1999. 'The Information-Technology Revolution and the Stock Market', American Economic Association Papers and Proceedings, vol. 89, pp. 116-122.

Hall, S. G.; Psaradakis, Z.; and Sola, M. 1999. Detecting Periodically Collapsing Bubbles: A Markov-Switching Unit Root Test. Journal of Applied Econometrics, 14 (March/April): 143-154.

Hall, S. G., and Sola, M. 1993. Testing for Collapsing Bubbles: An Endogenous Switching ADF Test. Discussion paper 15-93, London Business School, London.

Hand, J.R.M. and Landsman, W.R. 1999 The Pricing of Dividends in Equity Valuation Working paper, Kenan-Flagler Business School, University of North Carolina at Chapel Hill.

Hobijn, B. and Jovanovic B., 2000. 'The Information-Technology Revolution and the Stock Market: Evidence', NBER Working Paper, No. 7684.

Jovanovic, B., and Rob, R. 1990. Long Waves and Short Waves: Growth through Intensive and Extensive Search Econometrica 58(6), 1391-1409.

Kindleberger, C. P. 1989. Manias, Panics and Crashes: A History of Financial Crises. Macmillan, London.

Kleidon, A. W. 1986a. Variance Bounds Tests and Stock Price Valuation Models. Journal of Political Economy. 94 (October): 953-1001.

Kleidon, A. W. 1986b. Bias in Small Sample Tests of Stock Price Rationality. Journal of Business. 59 (April): $237-$ 261.

LeRoy, S. F., and Porter, R. D. 1981. The Present Value Relation: Tests Based on Implied Variance Bounds. Econometrica. 49 (May): 555-574.

McQueen, G., and Thorley, S. 1994. Bubbles, Stock Returns, and Duration Dependence. Journal of Financial and Quantitative Analysis. 29 (September): 379-401.

Meese, R. 1986. Testing for Bubbles in Exchange Markets: A case for Sparkling Rate. Journal of Political Economy. 94 (April): 345-373.

Rajgopal, S., Kotha, S., and Venkatchalam, M. 2000 The Relevance of Web Traffic for Internet Stock Prices Working paper, Stanford University.

Rappoport, P., and White, E. N. 1994. Was the Crash of 1929 Expected? American Economic Review, 84 (March): 271-281.

Salge, M. 1997. Rational Bubbles: Theoretical Basis, Economic Relevance and Empirical Evidence with a Special Emphasis on the German Stock Market. Springer, Berlin.

Shiller, R. J. 1981. Do Stock Prices Move Too Much to be Justified by Subsequent Changes in Dividends. American Economic Review. 71 (May): 421-36. 
Shiller, R. J. 2000. Irrational Exuberance. Princeton University Press, Princeton, New Jersey.

Sornette, D., and Johansen, A. 1997. Large Financial Crashes. Physica A, 245: 411-422.

Summers, L. H. 1986. Does the Stock Market Rationally Reflect Fundamental Values? Journal of Finance, 41 (July): 591-603.

van Norden, S. 1996. Regime Switching as a Test for Exchange Rate Bubbles. Journal of Applied Econometrics. 11 (May-June): 219-51.

van Norden S. and Schaller H., 1993. 'The Predictability of Stock Market Regime: Evidence from the Toronto Stock Exchange', The Review of Economics and Statistics, Vol. 75, pp. 505-510.

van Norden, S., and Schaller, H. 1997. Fads or Bubbles? Bank of Canada Working Paper no. 97-2.

van Norden, S., and Schaller, H. 1999. Speculative Behavior, Regime-Switching, and Stock Market Crashes. in Nonlinear Time Series Analysis of Economic and Financial Data, Philip Rothman ed.: 321-356.

Weil, P. 1990. On the Possibility of Price Decreasing Bubbles. Econometrica. 58 (November): 1467-1474.

West, K. D. 1988. Bubbles, Fads, and Stock Price Volatility Tests: A Partial Evaluation. Journal of Finance. 43 (July): 639-660.

West, K. 1987. A specification Test for Speculative Bubbles. Quarterly Journal of Economics. 102 (August): $553-580$.

White, E. N. 1990. The Stock Market Boom and Crash of 1929 Revisited. Journal of Economic Perspectives. 4 (Spring): 67-83.

Zeira J., 1999. 'Informational Overshooting, Booms and Crashes', Journal of Monetary Economics, vol. 43, pp. 237257. 
Table 1: Results of Augmented Bubble Model Including Volume for S\&P 500 Composite Index and Individual Sectors, 1973-2004

\begin{tabular}{|c|c|c|c|c|c|c|c|c|c|c|c|}
\hline & $\begin{array}{c}\text { S\&P } 500 \\
\text { Composite }\end{array}$ & $\begin{array}{l}\text { Cyclical } \\
\text { Services }\end{array}$ & Financials & $\begin{array}{c}\text { Basic } \\
\text { Industries }\end{array}$ & $\begin{array}{c}\text { General } \\
\text { Industrials }\end{array}$ & $\begin{array}{c}\text { Cyclical } \\
\text { Consumer } \\
\text { Goods }\end{array}$ & $I T$ & $\begin{array}{c}\text { Non- } \\
\text { Cyclical } \\
\text { Consumer } \\
\text { Goods }\end{array}$ & $\begin{array}{l}\text { Non- } \\
\text { cyclical } \\
\text { Services }\end{array}$ & Resources & Utilities \\
\hline $\bar{\beta} \beta_{S, 0}$ & $1.0186^{\star * *}$ & $1.0092^{* * *}$ & $1.0066^{\star \star \star}$ & $1.003^{* * *}$ & $1.0136^{* * *}$ & $1.0101^{* * *}$ & $1.0224^{\star \star *}$ & $1.0095^{\star \star \star}$ & $1.0119^{* * *}$ & $1.006^{* * *}$ & $1.008^{* * *}$ \\
\hline$\beta_{S, B}$ & $0.0227^{* *}$ & 0.0073 & $0.0246^{\star}$ & 0.0116 & $0.0825^{\star *}$ & $0.0186^{*}$ & $0.0582^{* * *}$ & 0.0056 & $0.0225^{\star \star}$ & 0.0049 & $-0.0265^{\star * *}$ \\
\hline$\beta_{S, V}$ & $-0.0287^{*}$ & 0.0192 & $-0.0351^{*}$ & 0.0021 & $-0.0271^{*}$ & -0.0068 & $-0.0108^{* * *}$ & -0.0091 & -0.0163 & -0.0067 & $-0.0308^{* *}$ \\
\hline$\beta_{C, 0}$ & $0.9874^{* * *}$ & $0.9896^{\star * *}$ & $1.0746^{\star * *}$ & $1.0225^{\star * *}$ & $1.0074^{\star * *}$ & $0.9927^{* * *}$ & $0.9624^{* \star *}$ & $1.0025^{\star \star \star}$ & $1.0001^{* * *}$ & $1.0212^{* \star *}$ & $1.1009^{* * *}$ \\
\hline$\beta_{C, B}$ & $-0.0308^{* *}$ & $-0.0619^{*}$ & $-0.2063^{\star * *}$ & $-0.1014^{*}$ & $-0.0434^{* *}$ & $-0.093^{\star *}$ & $-0.0394^{\star * *}$ & -0.0464 & $-0.0394^{\star *}$ & $-0.0542^{*}$ & $-0.0611^{* *}$ \\
\hline$\beta_{q, 0}$ & $1.0596^{* *}$ & $1.375^{\star}$ & $2.3178^{* * *}$ & $1.2909^{* *}$ & $0.9866^{\star *}$ & $1.2927^{\star * *}$ & $5.6283^{\star \star \star}$ & $1.7204^{\star * \star}$ & $2.0864^{* * *}$ & $1.2189^{* * *}$ & $2.8254^{* * *}$ \\
\hline$\beta_{q, B}$ & $-1.7218^{\star *}$ & -0.4902 & $-4.2231^{\star *}$ & -1.0328 & $-7.2097^{\star * \star}$ & $-1.6744^{\star \star}$ & $-7.9493^{\star * *}$ & -0.9381 & $-3.6056^{\star \star *}$ & $-2.131^{\star \star}$ & $-3.4791^{* * *}$ \\
\hline$\gamma_{q, V}$ & 1.7475 & -1.1952 & $-2.0186^{\star}$ & 0.0599 & $4.0695^{\star *}$ & 1.4841 & $3.3336^{\star \star *}$ & -2.3560 & -0.0743 & -0.2023 & $-1.4393^{*}$ \\
\hline$\sigma_{s}$ & $0.0309^{* * *}$ & $0.0455^{\star \star \star}$ & $0.0458^{* * *}$ & $0.0466^{* * *}$ & $0.0345^{\star * *}$ & $0.0437^{* * *}$ & $0.0644^{* \star *}$ & $0.0395^{\star * *}$ & $0.0333^{* * *}$ & $0.0404^{* * *}$ & $0.0378^{* * *}$ \\
\hline$\sigma_{C}$ & $0.0482^{* * *}$ & $0.081^{\star * *}$ & $0.0725^{\star \star \star}$ & $0.0999^{\star * *}$ & $0.062^{* * *}$ & $0.0773^{\star * *}$ & $0.0642^{* \star *}$ & $0.0877^{\star * *}$ & $0.0649^{\star * *}$ & $0.0809^{* * *}$ & $0.0263^{* * *}$ \\
\hline $\begin{array}{l}\text { Log-Likelihood } \\
\text { AIC } \\
\text { SIC } \\
\text { HQIC }\end{array}$ & $\begin{array}{c}585.6404 \\
-3.4993 \\
-3.3840 \\
-3.4533\end{array}$ & $\begin{array}{c}498.3641 \\
-2.9688 \\
-2.8534 \\
-2.9227\end{array}$ & $\begin{array}{c}551.9367 \\
-3.0108^{\star \star \star \star} \\
-2.9028 \\
-2.9678\end{array}$ & $\begin{array}{c}520.1957 \\
-2.8344 \\
-2.7265 \\
-2.7915\end{array}$ & $\begin{array}{c}529.3589 \\
-3.1193 \\
-3.0049 \\
-3.0737\end{array}$ & $\begin{array}{l}529.8356 \\
-2.8880 \\
-2.7800 \\
-2.8451\end{array}$ & $\begin{array}{l}420.4412 \\
-2.4215 \\
-2.3086 \\
-2.3765\end{array}$ & $\begin{array}{l}602.2093 \\
-3.2901 \\
-3.1821 \\
-3.2471\end{array}$ & $\begin{array}{c}587.2085 \\
-3.3461 \\
-3.2347 \\
-3.3018\end{array}$ & $\begin{array}{c}551.2288 \\
-3.0068 \\
-2.8989 \\
-2.9639\end{array}$ & $\begin{array}{c}642.4781 \\
-3.5138 \\
-3.4058 \\
-3.4708\end{array}$ \\
\hline$\beta_{S, 0} \neq \beta_{C, 0}$ & $4.0789^{\star \star}$ & 0.6926 & $7.1171^{\star \star \star}$ & 0.8743 & 0.5808 & 0.5804 & $17.4077^{* * \star}$ & 0.1142 & 1.3053 & 0.9479 & $8.8072^{* * *}$ \\
\hline$\beta_{C, B}<0$ & 1.6865 & $3.9269^{* *}$ & $9.0845^{\star * *}$ & $3.227^{*}$ & $3.9908^{\star *}$ & 2.3599 & $16.2619^{* * *}$ & 0.6558 & $5.0344^{* *}$ & 1.7849 & 2.1925 \\
\hline$\beta_{S, B}>\beta_{C, B}$ & $3.6458^{\star}$ & $2.7878^{\star}$ & $9.101^{\star \star *}$ & $3.3051^{*}$ & $6.6319^{* *}$ & 2.5068 & $28.7586^{\star \star *}$ & 0.7210 & $6.4252^{\star \star}$ & 1.2187 & 0.7986 \\
\hline$\beta_{S, V}>0$ & $4.5432^{\star \star}$ & 0.4256 & $5.7825^{\star \star}$ & 0.7481 & $12.3438^{\star \star \star}$ & 0.1997 & $45.2912^{\star \star \star}$ & 0.3513 & $11.4435^{\star \star \star}$ & $2.7657^{\star}$ & $4.8396^{\star \star}$ \\
\hline$\beta_{q, B}<0$ & $6.4481^{\star *}$ & 0.2476 & 2.2665 & 0.0022 & $7.4216^{\star \star \star \star}$ & 0.0038 & $4.7633^{\star \star}$ & 1.7532 & 0.0070 & 0.0366 & 0.9632 \\
\hline$\gamma_{q, V}<0$ & 1.4474 & 0.5390 & $3.2597^{\star}$ & 0.0140 & 1.6353 & 0.3598 & 0.0984 & 0.1751 & 1.3676 & 0.1260 & 0.3806 \\
\hline $\begin{array}{l}\text { Volatility Regimes } \\
\text { Mixture of Normals } \\
\text { Fads }\end{array}$ & $\begin{array}{c}14.2581^{\star *} \\
7.1192 \\
16.5008^{\star \star \star}\end{array}$ & $\begin{array}{l}7.4978 \\
6.8909 \\
6.5592\end{array}$ & $\begin{array}{l}20.3043^{\star \star \star} \\
16.9410^{\star \star *} \\
17.1395^{\star \star *}\end{array}$ & $\begin{array}{l}1.5772 \\
4.8116 \\
5.0683\end{array}$ & $\begin{array}{l}11.1616^{\star} \\
15.1737^{\star \star \star} \\
13.9322^{\star \star}\end{array}$ & $\begin{array}{l}2.0901 \\
3.2830 \\
3.3936\end{array}$ & $\begin{array}{l}42.0594^{\star \star \star} \\
45.4128^{\star \star \star} \\
45.3888^{\star \star \star}\end{array}$ & $\begin{array}{l}2.3541 \\
4.3627 \\
4.4522\end{array}$ & $\begin{array}{l}30.5537^{\star \star \star} \\
30.8772^{\star \star \star} \\
34.6006^{\star \star \star}\end{array}$ & $\begin{array}{l}3.6851 \\
4.9927 \\
4.0123\end{array}$ & $\begin{array}{c}11.5185^{\star} \\
4.9710 \\
7.9823\end{array}$ \\
\hline
\end{tabular}

Notes: The model is given by $r_{t+1}=\beta_{S, 0}+\beta_{S, b} B_{t}+\beta_{S, V} V_{t}^{x}+u_{t+1}^{S}, r_{t+1}=\beta_{C, 0}+\beta_{C, b} B_{t}+u_{t+1}^{C}, P\left(W_{t+1}=S\right)=q\left(B_{t}, V_{t}^{x}\right)=\Omega\left(\beta_{q, 0}+\beta_{q, b}\left|B_{t}\right|+\gamma_{q, V} V_{t}^{x}\right)$ with variable definitions given in the text. The second and third panels present likelihood ratio statistics which test restrictions that should hold for the bubble model to be a useful predictor and classifier of returns and to a set of simpler models respectively. ${ }^{*},{ }^{\star *}$ and ${ }^{\star \star \star}$ denote rejection of the null at the $90 \%, 95 \%$ and $99 \%$ confidence levels. 
Table 2: Results of Augmented Bubble Model Including Volume and Lagged Market Bubble Size and Market Volume for Individual Sectors, 1973-2004

\begin{tabular}{|c|c|c|c|c|c|c|c|c|c|c|}
\hline & $\begin{array}{l}\text { Cyclical } \\
\text { Services }\end{array}$ & Financials & $\begin{array}{c}\text { Basic } \\
\text { Industries }\end{array}$ & $\begin{array}{c}\text { General } \\
\text { Industrials }\end{array}$ & $\begin{array}{l}\text { Cyclical } \\
\text { Consumer } \\
\text { Goods }\end{array}$ & $I T$ & $\begin{array}{c}\text { Non- } \\
\text { Cyclical } \\
\text { Consumer } \\
\text { Goods }\end{array}$ & $\begin{array}{c}\text { Non- } \\
\text { cyclical } \\
\text { Services }\end{array}$ & Resources & Utilities \\
\hline$\overline{\beta_{s, 0}}$ & $0.9905^{\star * *}$ & $1.0139^{* * *}$ & $0.9812^{* \star *}$ & $1.0059^{* * *}$ & $1.0066^{* * *}$ & $1.9351^{* * *}$ & $0.9899^{* * *}$ & $1.0128^{* * *}$ & $1.0005^{\star \star \star}$ & $1.0112^{* \star *}$ \\
\hline$\beta_{S, B}$ & $-0.2644^{\star * *}$ & $-0.1846^{* * *}$ & $-0.2004^{* * *}$ & $-0.2904^{\star * *}$ & -0.0370 & $5.0721^{* * *}$ & $-0.1367^{\star * *}$ & $-0.1290^{* * *}$ & $-0.1048^{* * *}$ & $-0.1339^{* * *}$ \\
\hline$\beta_{S, V}$ & $0.0875^{\star \star *}$ & -0.0149 & 0.0368 & 0.0601 & 0.0143 & $-4.4209^{\star * *}$ & 0.0359 & 0.0048 & 0.0351 & -0.0070 \\
\hline$\beta_{c, 0}$ & $1.0081^{* * *}$ & 5.1304 & $1.0447^{* * *}$ & $2.0282^{\star \star \star}$ & $1.4387^{\star \star \star}$ & $1.0128^{\star \star \star}$ & $1.1540^{\star \star \star}$ & $1.0303^{\star \star *}$ & $1.0401^{* \star *}$ & $0.7529^{\star \star \star}$ \\
\hline$\beta_{C, B}$ & $-0.3895^{\star * *}$ & -8.5613 & -0.0786 & $-3.9612^{\star * *}$ & $-0.4547^{\star * *}$ & $0.0464^{*}$ & 0.0675 & -0.1150 & $0.3155^{\star \star}$ & $-0.2160^{*}$ \\
\hline$\beta_{q, 0}$ & $3.6805^{\star \star \star}$ & 7.0812 & $1.4824^{\star \star \star}$ & 4.5520 & 2.6108 & $-23.1501^{\star \star *}$ & 2463.4632 & $4.1505^{\star \star \star}$ & $6.2739^{\star \star \star}$ & $6.3754^{\star \star *}$ \\
\hline$\beta_{q, B}$ & $32.0605^{* * *}$ & -0.8042 & 1.3570 & -21.8595 & 0.9888 & $-15.9948^{* \star *}$ & -2599.1907 & $9.7092^{\star *}$ & $29.1776^{\star *}$ & -0.8078 \\
\hline$\gamma_{q, V}$ & $-11.5645^{\star * *}$ & -1.0157 & -0.9073 & -3.8705 & $-4.6352^{*}$ & $-2.4918^{\star * *}$ & -2442.1464 & 0.9234 & -2.4473 & 1.1361 \\
\hline$\sigma_{S}$ & $0.0474^{\star \star \star}$ & $0.0518^{* * *}$ & $0.0398^{\star * *}$ & 0.0468 & $0.0545^{\star \star *}$ & $1.1310^{* * *}$ & $0.0423^{\star \star \star}$ & $0.0357^{\star \star *}$ & $0.0487^{* \star *}$ & $0.0361^{\star * *}$ \\
\hline$\sigma_{C}$ & $0.0144^{* * *}$ & 0.3891 & $0.0605^{\star * *}$ & 0.0010 & 0.0010 & $0.0758^{\star * *}$ & $0.0414^{* * *}$ & $0.0659^{* * *}$ & $0.0610^{* * *}$ & $0.0470^{* * *}$ \\
\hline$\beta_{S, B, I}$ & $0.3558^{* * *}$ & $0.1436^{\star * *}$ & $0.2872^{* * *}$ & 0.2605 & 0.0429 & $7.6491^{* * *}$ & $0.1780^{* * *}$ & $0.1680^{* * *}$ & $0.0968^{* * *}$ & $0.1009^{* * *}$ \\
\hline$\beta_{S, V, I}$ & $-0.0826^{\star *}$ & 0.0199 & -0.0481 & -0.0442 & -0.0179 & $-1.9571^{\star * *}$ & -0.0441 & $-0.0388^{*}$ & $-0.0585^{\star *}$ & $-0.0280^{*}$ \\
\hline$\beta_{C, B, I}$ & $-0.4085^{\star \star \star}$ & -0.9301 & -0.0665 & $0.8795^{\star \star}$ & $-1.5729^{\star \star \star}$ & $-0.0753^{*}$ & $-0.3179^{\star \star}$ & 0.0269 & -0.0306 & $0.5862^{\star \star \star}$ \\
\hline$\beta_{q, B, I}$ & $-34.1712^{\star * *}$ & -1.0361 & $-5.3814^{\star * *}$ & 16.5431 & -0.6100 & $-10.5800^{* * *}$ & -2528.0929 & $-18.6835^{\star * *}$ & $-28.6416^{\star \star \star}$ & $-11.5833^{\star *}$ \\
\hline$\gamma_{q, V, I}$ & $8.9132^{\star *}$ & -0.8296 & $3.8272^{* *}$ & 8.4727 & 5.8865 & $-2.1070^{\star *}$ & 2132.0731 & 1.5539 & 0.5002 & $4.5067^{*}$ \\
\hline Volatility Regimes & $112.9696^{* \star *}$ & $23.7536^{\star * *}$ & $65.8893^{* \star \star}$ & $84.9888^{\star * \star}$ & 12.8359 & 0.3169 & $51.7346^{\star \star *}$ & $61.4459^{\star * \star}$ & $30.5902^{* \star *}$ & $50.9033^{* \star *}$ \\
\hline Mixture of Normals & $114.2201^{* * *}$ & $20.3904^{* * *}$ & $69.1237^{* * *}$ & $87.2057^{* \star *}$ & 14.0287 & 2.6648 & $53.7431^{* * *}$ & $62.1038^{* * *}$ & $31.8977^{* * *}$ & $44.3559^{* * *}$ \\
\hline Fads & $114.2609^{* * *}$ & $20.5889^{* * *}$ & $69.3804^{* * *}$ & $87.3704^{* \star *}$ & 14.1393 & 2.4465 & $53.8326^{\star * *}$ & $65.5218^{\star \star *}$ & $30.9174^{* * *}$ & $47.3671^{* * *}$ \\
\hline Augmented Model & $98.1606^{\star \star \star}$ & $13.7874^{\star \star *}$ & $64.3122^{* \star *}$ & $80.5064^{\star \star \star}$ & $10.4131^{*}$ & 0.0000 & $78.3386^{\star \star \star}$ & $27.1848^{\star \star \star}$ & $52.7603^{\star \star \star}$ & $47.5413^{\star \star \star}$ \\
\hline
\end{tabular}

Notes: The model is given by $r_{t+1}=\beta_{S, 0}+\beta_{S, b} B_{t}+\beta_{S, V} V_{t}^{x}+\beta_{S, b, I} B_{t, I}+\beta_{S, V, I} V_{t, I}^{x}+u_{t+1}^{S}, r_{t+1}=\beta_{C, 0}+\beta_{C, b} B_{t}+\beta_{C, b, I} B_{t, I}+u_{t+1}^{C}, P\left(W_{t+1}=S\right)=q\left(B_{t}, V_{t}^{x}\right)=\Omega\left(\beta_{q, 0}+\beta_{q, b}\left|B_{t}\right|+\gamma_{q, V} V_{t}^{x}+\beta_{q, b, I}\left|B_{t, I}\right|+\gamma_{q, V, I} V_{t, I}^{x}\right)$ with variable definitions given in the text. The second panel presents the likelihood ratio statistics for tests of restrictions to a set of simpler models. ${ }^{*},{ }^{* *}$ and ${ }^{* * *}$ denote rejection of the null at the $90 \%$, $95 \%$ and $99 \%$ confidence levels. 
Table 3: Results of Bubble Spillovers Model Including Lagged Bubble Size and Lagged Volume from All Ten Sectors, $1973-2004$

$\begin{array}{cc}\begin{array}{c}\text { Independent } \\ \text { Variables }\end{array} & \text { Param } \\ \text { Constant } & \beta_{s} \\ \text { Constant } & \beta_{c} \\ \text { Constant } & \beta_{q} \\ \text { Constant } & \sigma_{s} \\ \text { Constant } & \sigma_{c} \\ \text { Cyclical Services } & \beta_{s} \\ \text { Cyclical Services } & \beta_{c} \\ \text { Cyclical Services } & \beta_{q} \\ \text { Cyclical Services } & \beta_{s} \\ \text { Cyclical Services } & \gamma_{q,} \\ \text { Financials } & \beta_{s} \\ \text { Financials } & \beta_{c} \\ \text { Financials } & \beta_{q,} \\ \text { Financials } & \beta_{s} \\ \text { Financials } & \gamma_{q,} \\ \text { Basic Industries } & \beta_{s} \\ \text { Basic Industries } & \beta_{c} \\ \text { Basic Industries } & \beta_{q,} \\ \text { Basic Industries } & \beta_{s} \\ \text { Basic Industries } & \gamma_{q,} \\ \text { General Industrials } & \beta_{s} \\ \text { General Industrials } & \beta_{c} \\ \text { General Industrials } & \beta_{q} \\ \text { General Industrials } & \beta_{s} \\ \text { General Industrials } & \gamma_{q,} \\ \text { IT } & \beta_{s} \\ \text { IT } & \beta_{c} \\ \text { IT } & \beta_{q} \\ \text { clical Consumer Goods Consumer Goods } & \beta_{s} \\ \text { clical Consumer Goods } & \gamma_{q}, \\ \text { clical Consumer Goods } & \beta_{s} \\ \text { clical Consumer Goods } & \beta_{c} \\ \beta_{q} & \beta_{s} \\ & \end{array}$

\begin{tabular}{|c|c|c|}
\hline $\begin{array}{l}\text { Cyclical } \\
\text { Services }\end{array}$ & Financials & $\begin{array}{c}\text { Basic } \\
\text { Industries }\end{array}$ \\
\hline $1.0208^{\star * *}$ & $1.0225^{\star \star \star}$ & $1.0242^{\star \star \star}$ \\
\hline $0.8511^{\star * *}$ & $1.1086^{\star \star *}$ & $1.1787^{\star \star \star}$ \\
\hline $5.3630^{* * *}$ & $94.0263^{\star * *}$ & $47.3579^{\star \star *}$ \\
\hline $0.0500^{* * *}$ & $0.0487^{* * *}$ & $0.0505^{\star \star *}$ \\
\hline $0.0012^{\star * *}$ & 0.0010 & 0.0010 \\
\hline$-0.0850^{*}$ & -0.0417 & -0.0288 \\
\hline$-1.9818^{\star * *}$ & $-3.6896^{* * *}$ & $-3.9395^{\star * \star}$ \\
\hline-4.0061 & -23.9527 & $-43.0219^{* *}$ \\
\hline $0.0677^{*}$ & 0.0251 & -0.0088 \\
\hline$-8.5597^{\star \star *}$ & $-106.7719^{\star \star \star}$ & -0.1950 \\
\hline $0.1006^{\star *}$ & -0.0083 & $0.0638^{*}$ \\
\hline-0.0052 & $-2.2209^{\star \star *}$ & $4.3325^{\star \star \star}$ \\
\hline-2.5090 & $-100.2294^{* * *}$ & $-58.8132^{\star \star}$ \\
\hline 0.0244 & -0.0191 & -0.0024 \\
\hline$-8.7254^{\star * *}$ & $11.7304^{* *}$ & $123.2583^{* *}$ \\
\hline-0.0071 & 0.0081 & 0.0378 \\
\hline $0.2667^{\star *}$ & $-4.9518^{* * *}$ & $-4.7453^{\star \star *}$ \\
\hline 3.1526 & $118.2383^{\star * *}$ & 3.9511 \\
\hline $0.0928^{* * *}$ & 0.0215 & 0.0332 \\
\hline 1.0375 & $-13.2562^{* * *}$ & $-71.7334^{* *}$ \\
\hline$-0.0910^{*}$ & -0.0393 & $-0.1341^{\star *}$ \\
\hline$-1.0422^{\star \star *}$ & 0.8706 & $-2.5255^{\star \star *}$ \\
\hline$-23.9235^{\star * *}$ & $-237.6526^{\star \star \star}$ & $-94.5220^{* *}$ \\
\hline-0.0467 & -0.0457 & -0.0059 \\
\hline-0.9577 & $103.9577^{\star * *}$ & $42.2771^{* *}$ \\
\hline$-0.0551^{*}$ & $-0.0493^{*}$ & $-0.0863^{\star *}$ \\
\hline$-0.3131^{\star \star \star}$ & $5.6310^{* * *}$ & $-2.6936^{\star * *}$ \\
\hline $7.0866^{* *}$ & $-27.3120^{* * *}$ & 31.8614 \\
\hline$-0.0630^{* *}$ & -0.0273 & $-0.0482^{* *}$ \\
\hline 0.0171 & $-33.5130^{* * *}$ & 6.7443 \\
\hline $0.0695^{\star \star *}$ & $0.0732^{\star \star \star}$ & $0.0849^{\star * \star}$ \\
\hline $0.9081^{\star * *}$ & $-3.5741^{* * *}$ & $-1.9164^{\star \star \star}$ \\
\hline $7.4795^{\star}$ & $-3.5430^{*}$ & -2.5529 \\
\hline 0.0048 & $0.0532^{* \star}$ & 0.0084 \\
\hline
\end{tabular}

\begin{tabular}{|c|c|c|}
\hline \multirow[b]{2}{*}{$\begin{array}{l}\text { General } \\
\text { Industrials }\end{array}$} & \multicolumn{2}{|c|}{ Dependent Variables } \\
\hline & $\begin{array}{l}\text { Cyclical } \\
\text { Consumer } \\
\text { Goods }\end{array}$ & $I T$ \\
\hline $1.0139^{\star \star \star}$ & $1.0263^{* \star \star}$ & $1.3264^{\star \star \star}$ \\
\hline $0.9822^{\star \star \star}$ & $1.4400^{\star \star \star}$ & $1.0081^{\star \star *}$ \\
\hline $6.9964^{* * *}$ & $5.5706^{\star *}$ & -3.0636 \\
\hline $0.0476^{* * *}$ & $0.0468^{* * *}$ & 0.2495 \\
\hline $0.0011^{* * *}$ & 0.0010 & $0.0745^{\star * *}$ \\
\hline-0.0176 & -0.0276 & -0.1633 \\
\hline$-2.8932^{\star * *}$ & $-3.3476^{\star * *}$ & 0.0085 \\
\hline$-6.3126^{*}$ & 0.4281 & -1.6582 \\
\hline $0.0705^{\star *}$ & 0.0449 & 0.2546 \\
\hline 0.9015 & $-8.0186^{\star *}$ & 0.0331 \\
\hline $0.0596^{*}$ & 0.0671 & -0.0916 \\
\hline $0.3823^{\star \star \star}$ & $-3.4180^{\star \star \star}$ & 0.0350 \\
\hline-0.8735 & 0.1188 & -1.2145 \\
\hline-0.0342 & 0.0445 & 0.5736 \\
\hline 0.4161 & -1.0598 & 0.1426 \\
\hline 0.0351 & 0.0444 & 0.4987 \\
\hline$-1.8866^{\star * *}$ & $-5.0659^{\star * *}$ & 0.0232 \\
\hline-1.9280 & 9.9398 & -1.1774 \\
\hline 0.0350 & $0.0635^{\star \star}$ & -0.0260 \\
\hline 0.7331 & $-2.7629^{\star *}$ & -0.0212 \\
\hline$-0.1420^{\star \star \star}$ & -0.0577 & -0.1503 \\
\hline$-0.5948^{\star * *}$ & $1.5183^{* \star *}$ & $-0.1893^{\star * *}$ \\
\hline-6.9172 & -7.1158 & -1.2536 \\
\hline 0.0310 & -0.0242 & 0.1494 \\
\hline 1.4426 & 7.5886 & 0.1380 \\
\hline-0.0395 & $-0.0908^{\star \star \star}$ & 0.2177 \\
\hline $0.4596^{* * *}$ & $3.1439^{* * *}$ & -0.0180 \\
\hline 1.3046 & -2.3029 & -1.3104 \\
\hline$-0.0548^{\star *}$ & -0.0363 & -0.0190 \\
\hline $2.2407^{\star \star}$ & 0.8306 & 0.2094 \\
\hline $0.0480^{* *}$ & $0.0753^{\star *}$ & -0.1839 \\
\hline$-0.2351^{* * *}$ & $-1.1318^{\star * \star}$ & $0.0443^{*}$ \\
\hline $5.4524^{*}$ & 1.8895 & -3.4684 \\
\hline 0.0070 & -0.0519 & -0.1382 \\
\hline
\end{tabular}

Non-Cyclical
Consumer
Goods
$1.0143^{* *}$
-0.0178
26.9564
0.0422
0.0010
-0.0036
-5.2194
-4.8420
0.0236
44.2501
0.0564
-1.0737
-58.4438
0.0037
18.1092
0.0259
-5.5617
16.4504
0.0329
42.3712
-0.0870
0.1632
-3.3474
-0.0065
-14.5121
-0.0787
3.8262
15.2511
-0.0319
-51.3280
0.0611
4.7513
-18.0153
-0.0015

Non-

Cyclical

Services

$1.0163^{* * \star}$

1.1746

$21.3602^{* * *}$

$0.0439^{\star * *}$

0.0010

$-0.0512$

$-1.2263$

$-2.9367^{\star \star \star}$

0.0255

$4.5244^{\star *}$

0.0060

0.8763

$-5.6785^{\star \star \star}$

0.0154

0.7556

0.0098

$-11.8384^{\star *}$

$5.8971^{* * *}$

$-0.0092$

$-4.6970^{\star \star \star *}$

$-0.0008$

5.6994

$5.6445^{\star * *}$

0.0084

0.8238

0.0104

$7.8083^{*}$

$-8.5779^{\star \star *}$

$-0.0210$

Resources

Utilities

$1.0179^{\star * *}$

$1.0476^{* *}$

$1.0101^{* * *}$

2151.2003

$0.0473^{\star * *}$

$0.0189^{\star \star \star}$

5.1465

5.1465
$0.0393 * * *$

$0.9037^{* * *}$

0.4113

0.0143

$-5.1549$

$\begin{array}{ll}-0.0058 & 0.3681\end{array}$

$\begin{array}{ll}-0.0097 & -0.0231\end{array}$

$\begin{array}{ll}-0.0097 & -0.0231 \\ -1018.0476 & -0.5453\end{array}$

0.0019

$3158.6089 \quad-0.1282$

$-3.1893^{\star \star *} \quad-0.6015$

$1296.1547 \quad-0.1096$

$\begin{array}{rr}-2288.9338 & -0.0263 \\ -0.0622\end{array}$

$\begin{array}{ll}-0.0258 & 0.0126\end{array}$

$\begin{array}{ll}-1.5786^{\star \star \star} & 1.7607\end{array}$

$\begin{array}{ll}-313.9704 & 0.0827\end{array}$

$-0.0123 \quad 0.0043$

$-586.9348 \quad-0.1694$

$-0.0500^{*} \quad-0.0026$

$1.4890^{* \star *} \quad-5.5961$

$2259.5074 \quad-0.1795$

$\begin{array}{rrr}-20.6840^{* * *} & -1522.8705 & -0.0488^{* *} \\ -0.0296^{*} & 0.0377 * * & -0.7357\end{array}$

$0.0296^{*} \quad 0.0377^{* *}$

\begin{tabular}{lll}
0.2190 & $-0.6873^{\star \star *}$ & 0.0049 \\
\hline $4.7060^{* *}$ & 3540.4437 & 0.2565
\end{tabular}

$-4.7060^{* * *} \quad 3540.4437 \quad 0.2565$

$\begin{array}{lll}-0.0323^{\star} & 0.0160 & -0.0032\end{array}$ 


\begin{tabular}{|c|c|c|c|c|c|c|c|c|c|c|c|}
\hline \multirow[b]{2}{*}{$\begin{array}{l}\text { Independent } \\
\text { Variables }\end{array}$} & \multirow[b]{2}{*}{ Parameter } & \multirow[b]{2}{*}{$\begin{array}{l}\text { Cyclical } \\
\text { Services }\end{array}$} & \multirow[b]{2}{*}{ Financials } & \multirow[b]{2}{*}{$\begin{array}{c}\text { Basic } \\
\text { Industries }\end{array}$} & \multirow[b]{2}{*}{$\begin{array}{c}\text { General } \\
\text { Industrials }\end{array}$} & \multicolumn{2}{|c|}{ Dependent Variables } & \multirow[b]{2}{*}{$\begin{array}{l}\text { Non-Cyclical } \\
\text { Consumer } \\
\text { Goods }\end{array}$} & \multirow[b]{2}{*}{$\begin{array}{l}\text { Non- } \\
\text { Cyclical } \\
\text { Services }\end{array}$} & \multirow[b]{2}{*}{ Resources } & \multirow[b]{2}{*}{ Utilities } \\
\hline & & & & & & $\begin{array}{l}\text { Cyclical } \\
\text { Consumer } \\
\text { Goods }\end{array}$ & $I T$ & & & & \\
\hline$I T$ & $\gamma_{q, V}$ & $2.8881^{*}$ & $9.9841^{* *}$ & 5.8563 & $3.3995^{\star *}$ & 2.8964 & -0.8976 & -5.0175 & $15.9634^{\star \star *}$ & 1911.7878 & 0.4755 \\
\hline Non-Cyclical Consumer Goods & $\beta_{S, B}$ & $0.0713^{*}$ & 0.0237 & 0.0215 & -0.0084 & 0.0159 & 0.2862 & -0.0404 & $0.0515^{*}$ & -0.0367 & 0.0223 \\
\hline Non-Cyclical Consumer Goods & $\beta_{C, B}$ & $-0.4757^{\star \star \star}$ & -1.3710 & $2.9596^{\star * *}$ & $0.1127^{\star * *}$ & $4.6554^{\star * *}$ & -0.0208 & -4.0444 & -2.2972 & $1.2815^{\star * *}$ & 1.8025 \\
\hline Non-Cyclical Consumer Goods & $\beta_{q, B}$ & $6.5905^{\star \star}$ & 11.4096 & $34.5454^{*}$ & -0.8434 & -6.4834 & -1.1988 & -15.3163 & $-3.8383^{*}$ & -5922.0681 & 0.1660 \\
\hline Non-Cyclical Consumer Goods & $\beta_{S, V}$ & -0.0346 & -0.0187 & 0.0263 & -0.0350 & -0.0366 & 0.1752 & -0.0176 & -0.0316 & 0.0411 & 0.0266 \\
\hline Non-Cyclical Consumer Goods & $\gamma_{q, V}$ & $-4.4806^{*}$ & $-134.3989^{* * *}$ & $-71.5682^{* *}$ & $-12.4497^{* * *}$ & -6.1719 & 0.1286 & -19.0856 & -0.3591 & -128.1544 & 0.4792 \\
\hline Non-Cyclical Services & $\beta_{S, B}$ & -0.0482 & -0.0400 & $-0.0707^{* *}$ & 0.0371 & $-0.1515^{\star * *}$ & -0.1113 & 0.0082 & -0.0317 & -0.0436 & 0.0458 \\
\hline Non-Cyclical Services & $\beta_{C, B}$ & $2.4376^{\star \star \star}$ & $4.8498^{\star \star *}$ & $4.6147^{\star \star *}$ & $3.7269^{* * *}$ & $2.1327^{\star \star *}$ & $0.1012^{*}$ & -0.5018 & 1.6950 & $0.7705^{\star \star *}$ & 3.4895 \\
\hline Non-Cyclical Services & $\beta_{q, B}$ & 2.4774 & $-62.9097^{* * *}$ & -1.8750 & -3.2554 & $-4.2270^{\star *}$ & -1.3774 & $60.5460^{* *}$ & $-15.8206^{\star \star \star}$ & -3789.8572 & 0.3127 \\
\hline Non-Cyclical Services & $\beta_{S, V}$ & $-0.0292^{* *}$ & -0.0074 & 0.0075 & -0.0135 & -0.0112 & -0.0666 & -0.0112 & -0.0113 & -0.0133 & -0.0070 \\
\hline Non-Cyclical Services & $\gamma_{q, V}$ & 0.6619 & $47.3218^{* * *}$ & $-54.9774^{*}$ & -0.1756 & 2.6090 & 0.1148 & 5.6562 & $23.3812^{* \star *}$ & 888.0552 & 0.0893 \\
\hline Resources & $\beta_{S, B}$ & $-0.0456^{*}$ & $-0.0673^{* * *}$ & $-0.0757^{* \star *}$ & $-0.0450^{* *}$ & $-0.1045^{\star * *}$ & -1.0305 & -0.0539 & $-0.0520^{\star * *}$ & $-0.0662^{\star \star *}$ & $-0.0360^{\star *}$ \\
\hline Resources & $\beta_{C, B}$ & $-0.4737^{\star \star \star}$ & $5.0891^{* * *}$ & $5.0672^{\star \star *}$ & $0.6703^{\star * *}$ & 0.0104 & -0.0388 & 6.4065 & $-6.5111^{*}$ & $0.6321^{* * *}$ & -3.5904 \\
\hline Resources & $\beta_{q, B}$ & 0.3222 & $31.4004^{*}$ & -5.6513 & $3.6990^{* *}$ & -7.9814 & -1.3119 & -12.9559 & $8.4456^{* * *}$ & -1363.0846 & 0.6758 \\
\hline Resources & $\beta_{S, V}$ & $-0.0355^{\star}$ & 0.0116 & -0.0227 & -0.0318 & -0.0162 & 0.4347 & -0.0020 & $0.0305^{\star}$ & $0.0424^{* *}$ & 0.0271 \\
\hline Resources & $\gamma_{q, V}$ & $8.5458^{\star * *}$ & $-11.4180^{\star}$ & $34.1881^{\star \star \star}$ & $3.3013^{* *}$ & -1.4795 & 0.1313 & -22.1181 & $-14.2386^{\star \star \star}$ & 285.8898 & -0.0260 \\
\hline Utilities & $\beta_{S, B}$ & $0.0690^{\star}$ & $0.0842^{* *}$ & $0.1271^{* * *}$ & 0.0237 & $0.2106^{\star \star *}$ & -0.0665 & 0.0587 & 0.0080 & $0.0762^{*}$ & $-0.0704^{\star \star}$ \\
\hline Utilities & $\beta_{C, B}$ & $0.3450^{* * *}$ & $1.2004^{* *}$ & $-0.6448^{* * *}$ & -0.0156 & $0.6860^{* * *}$ & -0.0033 & 0.5190 & 0.6783 & $-2.9751^{* * *}$ & -7.0657 \\
\hline Utilities & $\beta_{q, B}$ & -1.2781 & $249.9852^{* \star *}$ & $124.6569^{\star *}$ & $-3.2515^{*}$ & 10.9064 & -1.0204 & -5.0214 & $2.8133^{* *}$ & 5178.5693 & -1.4498 \\
\hline Utilities & $\beta_{S, V}$ & -0.0066 & -0.0195 & -0.0022 & 0.0114 & -0.0297 & 0.9266 & -0.0215 & -0.0130 & -0.0079 & -0.0057 \\
\hline Utilities & $\gamma_{q, V}$ & $11.1089^{\star \star *}$ & $106.6774^{\star \star *}$ & -4.5222 & 0.5734 & 3.3115 & 0.0293 & 17.1441 & $13.8373^{\star \star *}$ & 515.7842 & -0.2057 \\
\hline Volatility Regimes & & $150.0727^{\star \star \star}$ & $154.8886^{* \star \star}$ & $182.8337^{\star \star \star}$ & $129.5272^{\star \star \star}$ & $175.3643^{\star \star \star}$ & 12.4096 & $102.4392^{\star \star \star}$ & $87.8353^{* * *}$ & $106.4341^{* \star *}$ & 30.7490 \\
\hline Mixture of Normals & & $151.3232^{\star \star \star}$ & $151.5254^{\star \star \star}$ & $186.0681^{\star \star \star}$ & $131.7440^{\star \star \star}$ & $176.5571^{\star * \star}$ & 14.7575 & $104.4477^{\star * *}$ & $88.4932^{\star \star *}$ & $107.7417^{\star \star *}$ & 24.2015 \\
\hline Fads & & $151.3639^{\star * *}$ & $151.7239^{\star * *}$ & $186.3248^{* * *}$ & $131.9087^{* * *}$ & $176.6677^{\star \star *}$ & 14.5393 & $104.5372^{* * *}$ & $91.9112^{\star * *}$ & $106.7614^{\star * *}$ & 27.2128 \\
\hline Augmented Model & & $135.2637^{\star \star \star}$ & $144.9224^{\star \star *}$ & $181.2565^{\star \star \star}$ & $125.0447^{\star \star \star}$ & $172.9415^{\star \star \star}$ & 0.0000 & $129.0432^{\star \star \star}$ & 53.5742 & $128.6043^{\star \star *}$ & 27.3870 \\
\hline Agumented model + market-wide & ubble terms & 37.1031 & $131.1350^{\star * *}$ & $116.9444^{\star \star \star}$ & 44.5383 & $162.5284^{\star \star *}$ & 12.0928 & 50.7046 & 26.3894 & $75.8440^{\star \star *}$ & 0.0000 \\
\hline
\end{tabular}

given in the text. The second panel presents the likelihood ratio statistics for tests of restrictions to a set of simpler models. ${ }^{*},{ }^{* *}$ and ${ }^{* \star *}$ denote rejection of the null at the $90 \%$, $95 \%$ and $99 \%$
confidence levels. 
Figure 1: S\&P 500 Information Technology Price Index and Dividend Yield January 1973 - June 2004

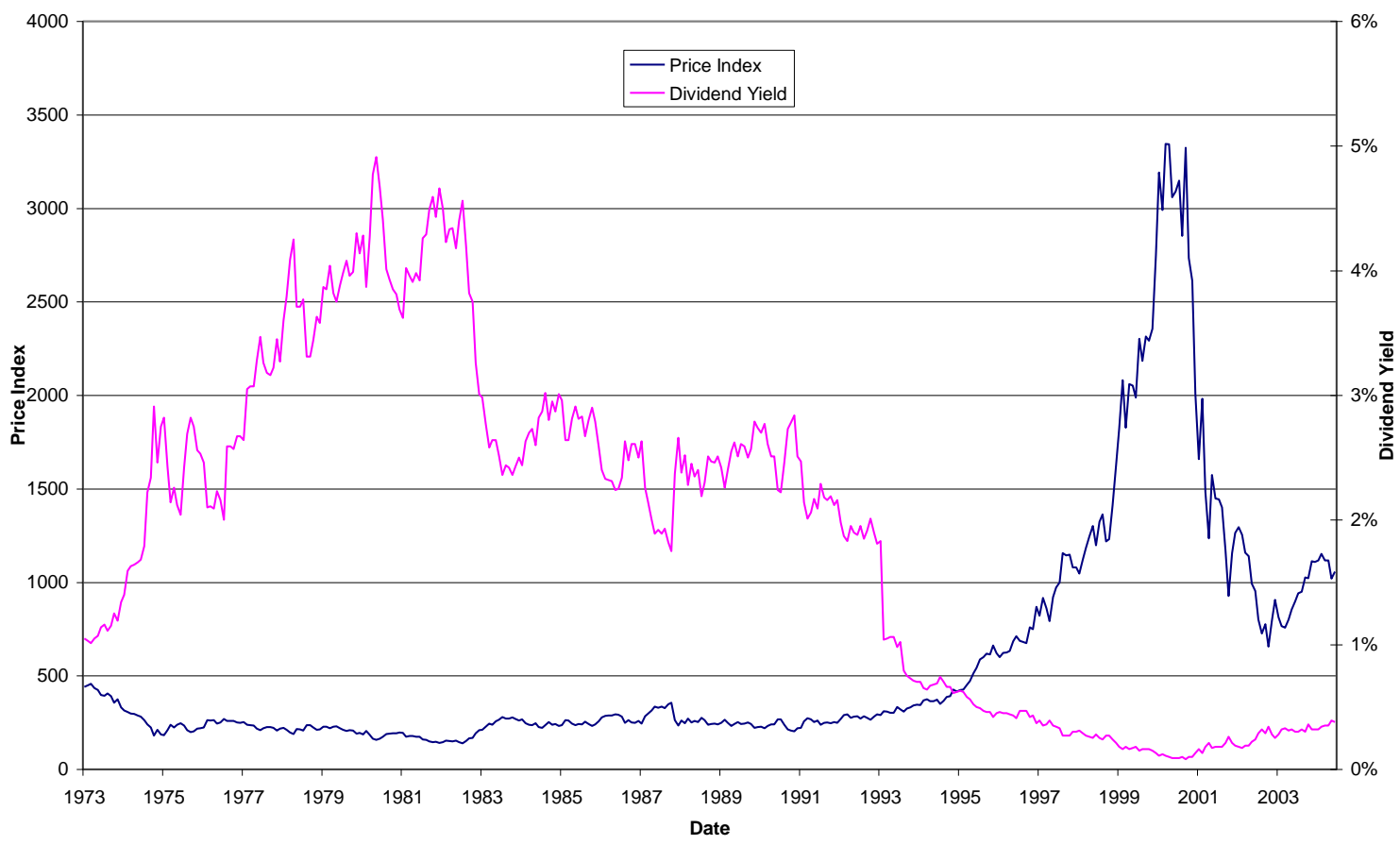

Figure 2: S\&P 500 General Industrials Price Index and Dividend Yield January 1973 - June 2004

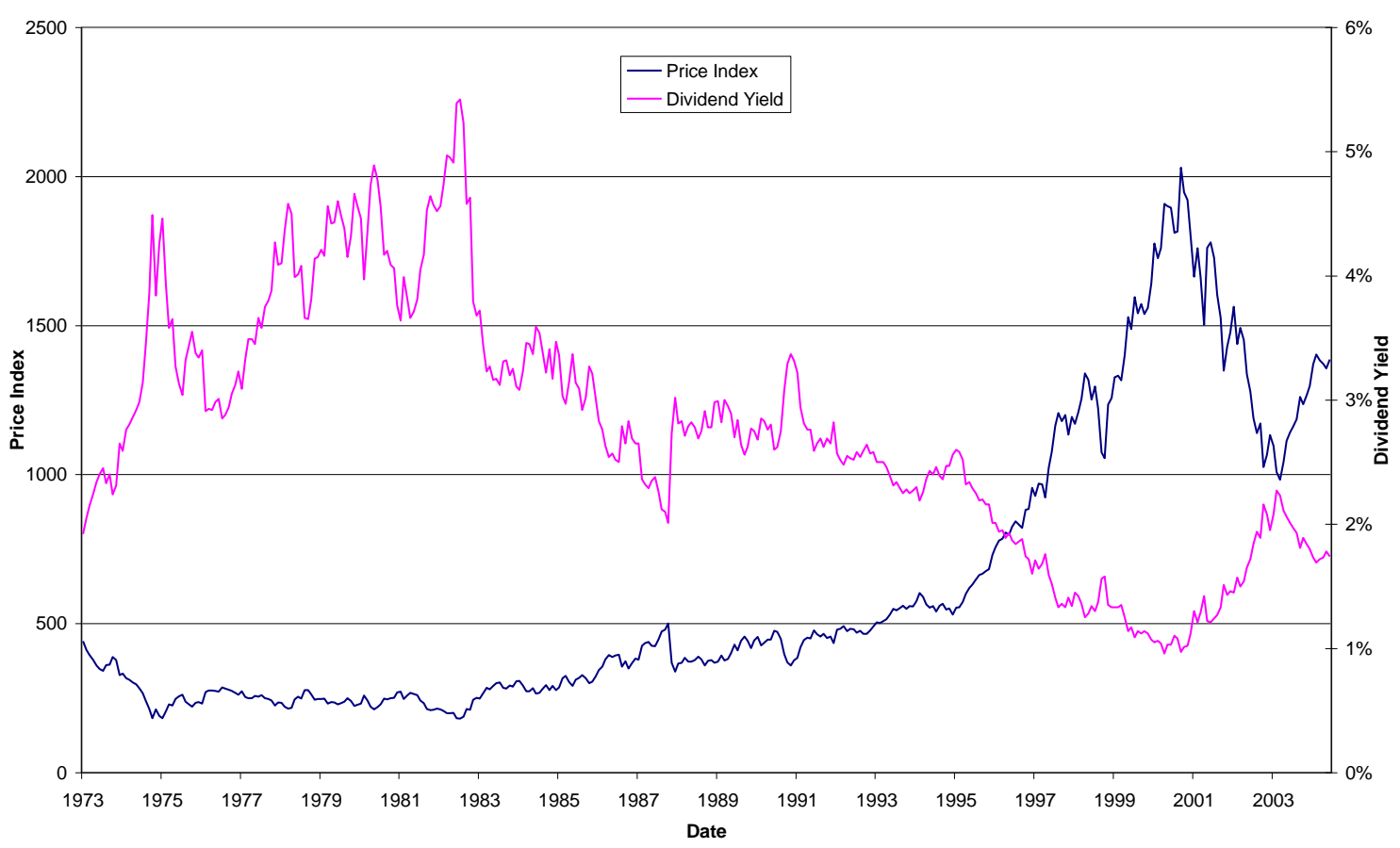


Figure 3: S\&P 500 Resources Price Index and Dividend Yield January 1973 - June 2004



